IZA DP No. 5454

The Role of Marriage in the Causal Pathway from Economic Conditions Early in Life to Mortality

Gerard J. van den Berg

Sumedha Gupta

January 2011 


\title{
The Role of Marriage in the Causal Pathway from Economic Conditions Early in Life to Mortality
}

\author{
Gerard J. van den Berg \\ University of Mannheim, VU University Amsterdam, \\ IFAU-Uppsala and IZA \\ Sumedha Gupta \\ Indiana University-Purdue University Indianapolis
}

\author{
Discussion Paper No. 5454 \\ January 2011
}

IZA

P.O. Box 7240

53072 Bonn

Germany

Phone: +49-228-3894-0

Fax: +49-228-3894-180

E-mail: iza@iza.org

\begin{abstract}
Any opinions expressed here are those of the author(s) and not those of IZA. Research published in this series may include views on policy, but the institute itself takes no institutional policy positions.

The Institute for the Study of Labor (IZA) in Bonn is a local and virtual international research center and a place of communication between science, politics and business. IZA is an independent nonprofit organization supported by Deutsche Post Foundation. The center is associated with the University of Bonn and offers a stimulating research environment through its international network, workshops and conferences, data service, project support, research visits and doctoral program. IZA engages in (i) original and internationally competitive research in all fields of labor economics, (ii) development of policy concepts, and (iii) dissemination of research results and concepts to the interested public.
\end{abstract}

IZA Discussion Papers often represent preliminary work and are circulated to encourage discussion. Citation of such a paper should account for its provisional character. A revised version may be available directly from the author. 
IZA Discussion Paper No. 5454

January 2011

\section{ABSTRACT \\ The Role of Marriage in the Causal Pathway from Economic Conditions Early in Life to Mortality ${ }^{*}$}

This paper analyzes the interplay between early-life conditions and marital status, as determinants of adult mortality. We use individual data from Dutch registers (years 18152000), combined with business cycle conditions in childhood as indicators of early-life conditions. The empirical analysis estimates bivariate duration models of marriage and mortality, allowing for unobserved heterogeneity and causal effects. Results show that conditions around birth and school ages are important for marriage and mortality. Men typically enjoy a protective effect of marriage on mortality, whereas women suffer during childbearing ages. Having been born under favorable economic conditions reduces female mortality during childbearing ages.

JEL Classification: I12, J14, E32, N33, N13, C41

Keywords: death, longevity, recession, life expectancy, lifetimes, marital status, timing of events, selectivity, health

Corresponding author:

Sumedha Gupta

524 Cavanaugh Hall

Department of Economics

IUPUI

Indianapolis, IN 46202-5147

USA

E-mail: sugupta@iupui.edu

\footnotetext{
*We are grateful to Andrew Chesher, James Banks, Ronald Wolthoff, Marta López, Erik Plug, Maarten Lindeboom, Kees Mandemakers, and Manuel Arellano, for valuable comments on an earlier version of this paper. We also thank participants of PAA, ESEM, and ESPE conferences, the IZA Summer School, the Microdata meeting at CEMFII, a gender conference at IAB/University of Nürnberg, seminars at the Tinbergen Institute and UCL, and workshops of the Max Planck Institute for Demographic Research on "Causal inference and endogeneity in event history analysis" and "Early-life vs. later-life effects on late-life mortality" for their useful input. The "Historical Sample of the Netherlands Dataset Release UZF.02" was kindly provided by the International Institute of Social History (IISG), Amsterdam. The authors acknowledge financial support from the EU 6th Research Framework and Marie Curie Research Training Actions.
} 


\section{Introduction}

Socioeconomic conditions during infancy and childhood and marriage are by now well established predictors of adult health and mortality. Poor socioeconomic status, leading to poor nutrition, and greater exposure to diseases in-utero and during childhood are associated with increased vulnerability to a whole range of health problems and lower life expectancy (see e.g. Case et al., 2003, Doblhammer, 2004, and Van den Berg et al., 2006). Marriage also affects mortality, with married men exhibiting lower susceptibility to health problems like cardiovascular diseases and consequently exhibit higher life expectancy (Phillips et al., 2001).

Unlike the clear direction of the association between early life conditions and mortality, the relationship between marriage and mortality could be bidirectional. Marriage could involve direct material ${ }^{1}$ or emotional transfers and care giving from the spouse, which could increase the well-being of a married individual. More indirectly, married individuals may experience lower psychological stress owing to a favorable societal attitude towards married individuals (Van Poppel, 1992), lead healthier lifestyles (lower consumption of alcohol or smoking) and adopt less risk taking behavior which could decrease risk of mortality. Consequently, marriage may be 'protective' against mortality (Johnson et al., 2000, Lund et al., 2004, Gardner and Oswald, 2004, and Murray, 2000). But several studies also find support for a 'selection' into marriage (e.g. Goldman 1993a, 1993b) according to which a range of factors like age, health, social background, income, occupation, education and race might affect marriage as well as mortality. ${ }^{2}$ Better health, for instance, of married persons is then a consequence of the selection of 'healthy' persons into and 'unhealthy' individuals out of marriage. Any such positive selection into marriage would overstate the average causal effect of marriage on mortality at the individual level. The causal and the selection effect could both explain the lower mortality of married individuals (for e.g. see $\mathrm{Hu}$ and Goldman, 1990, Lillard and Panis, 1996). The difficulty to control for confounding factors makes it challenging to distinguish between these effects.

This study analyzes the interplay between early life conditions and marriage as determinants of high-age mortality. Specifically, we focus on the extent to which early-life conditions influence the positive or negative effect of marriage on mortality, and we consider the extent to which early-life conditions influence the entry rate into marriage (which we call the "marriage rate"). Figure 1 presents potential pathways between early life, marriage and later-life mortality. It contains four arrows, where the arrow that originates at birth and targets the arrow from marriage to mortality represents the interaction effect of early-life conditions and marriage on mortality. As noted in the previous paragraphs, the arrow from early-life condi-

\footnotetext{
${ }^{1}$ For example by means of economies of scale and specialization within the household (Gardner and Oswald, 2004).

${ }^{2}$ For instance, factors like job security, high social background, high income, and education (Gardner and Oswald, 2004) increase one's marriage prospects and also favorably affect the individual's survival.
} 


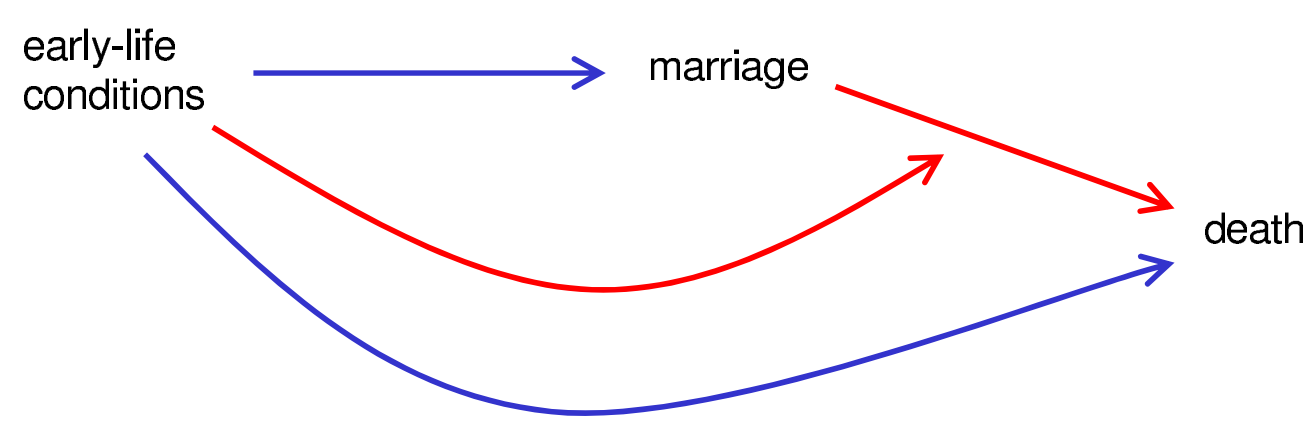

0

age

Figure 1: Pathways between early life conditions, marriage, and mortality, over an individual's lifetime.

tions to mortality and the arrow from marriage to mortality have been studied extensively. We focus on the other two arrows: the impact of economic conditions early in life on the individual rate of getting married, and the extent to which the protective effect of marriage depends on conditions early in life. However, for this purpose, all four arrows need to be analyzed simultaneously in the empirical analysis.

The results of the analysis shed light on the extent to which the effect of early life conditions on mortality later in life is channeled through marital status. More specifically, the results shed light on the use of marriage as a compensatory device in case of adverse early-life conditions. We are interested in the question whether individuals born in adverse conditions benefit from a larger protective effect of marriage on the mortality rate. Moreover, we want to know whether individuals born under adverse conditions marry earlier. If the protective effect is larger for them then this provides an incentive to marry earlier. Conversely, they may marry later because they may have worse opportunities in the marriage market.

As such, our paper is informative on the degree to which an economically bad start in life can be compensated by deliberate social behavior at prime age, and it is informative on the degree to which such a pathway is used by those for whom the gains are highest.

The empirical agenda sketched above faces two major selectivity problems. First, the actual economic conditions in the household early in life are potentially endogenous as an 
explanation of events later in life, because of shared unobserved confounders. Secondly, marriage is potentially endogenous for mortality. To deal with the first problem, we use business cycle conditions in early years of life as an indicator of individual economic well-being. This is in line with the recent literature in which natural experiments or transitory fluctuations in contextual variables are used for this purpose. In the case of the business cycle, several studies have explained and used this approach; see e.g. Van den Berg et al. (2006, 2011). Since macroeconomic conditions are exogenous at the individual level, this indicator of economic conditions in early years of life does not suffer from confounding.

To deal with the second selectivity problem, i.e., to control for any joint unobserved heterogeneity affecting both marriage and mortality, we model the individual's entry rate into marriage and the mortality rate simultaneously, allowing for selection on unobservables. We apply the so-called Timing-of-Events approach formalized by Abbring and Van den Berg (2003) to identify the causal effect of marriage. This approach requires some amount of randomness in the moment of marriage, which may be justified by the random nature of the arrival of opportunities in the marriage market. For given conditions early in life, the identification of the marriage effect does not require an instrumental variable for marriage. We discuss the identification strategy in more detail in the paper.

To date, there is no extensive literature on the effect of early-life conditions on marriage and on its effect on the extent to which marriage postpones mortality. Phillips et al. (2001) suggest that prenatal growth provides a link between marital status and mortality. Using a Finnish data set of male births, the authors note that the marriage rate is positively related to birth conditions like weight, height, head circumference, gestational age, even after controlling for a wide range of factors like adult health ${ }^{3}$ and socioeconomic background characteristics. The authors hypothesize that fetal conditions may affect an individual's personality, socialization, sexuality and emotional responses in later life, consequently affecting their marital status and mortality later in life. This result is contradicted by Vågerö and Modin (2002) who, using a Swedish longitudinal panel covering individuals from birth to death, find no differences in mortality between ever married and never married women before and after adjusting for prenatal conditions, ${ }^{4}$ once socioeconomic background (like marital status of mother, social class at birth) and adult conditions (occupation, education and income) have been controlled for. The same result is obtained for men, although married men are less likely to suffer from heart diseases and stroke than unmarried men, the risk ratios remain unaffected when social factors at birth are adjusted for. The authors conclude that there is no evidence for early health status in life being the factor explaining differences in mortality across different marital statuses. Clearly, the studies by Phillips et al. (2001) and Vågerö and Modin (2002) are innovative, but they do not focus on selection on unobservables, and

\footnotetext{
${ }^{3}$ Measured using height and weight at age 15 .

${ }^{4}$ The authors use birth weight for gestational age as a measure of fetal growth.
} 
the findings are inconclusive on the presence and magnitude of the causal effects that we are interested in.

A joint study of conditions early in life, marriage and mortality requires individual data covering a large time window. In this paper we use records from Dutch registers of birth, marriage and death certificates, covering 1815-2000. These individual level data are then combined with indicators of historical macro conditions. The individual register data have been used in a wide range of studies (see Mandemakers, 2000, for an overview) including studies on the effect of early-life conditions on mortality (Van den Berg et al., 2006, 2009). These studies have ignored marital status as an intermediate outcome between birth and death. The data have also been used in descriptive studies of determinants of the marriage rate and in studies on the association between marital status and mortality (see e.g. Van Poppel and Joung, 2001), though not addressing the issues we focus on.

Our results show that conditions around birth as well as around school ages are important for marital status and mortality. The results are strikingly different across gender. Men on average enjoy a protective effect of marriage on mortality. Women born in economic booms gain from marriage during childbearing ages, but women born in recessions suffer a substantial negative effect on life expectancy during these years.

Section 2 describes the individual data. The empirical approach is discussed in Section 3. Section 4 presents the estimation results along with sensitivity analyses and implications. Section 5 concludes.

\section{Individual data records}

The Historical Sample of the Netherlands $(\mathrm{HSN})^{5}$, dataset project Utrecht-Zeeland-Friesland 02 (UZF.02), is created by merging individual data from Dutch registers of birth, marriage and death certificates. It includes a random sample of individuals born in one of the three provinces of Utrecht, Friesland or Zeeland ${ }^{6}$ between 1812-1922. The last day of observation of the sample is December 31, 1999. It records key events in an individual's life - birth, marriage and death- and also includes information on occupation of parents, gender and geographical location. As noted above, the data have been used in numerous other studies, so the present exposition can be brief.

Individual lifetime durations are noted in days. If the individual is still alive at the end of 1999, the date of death is not observed. The lifetime durations of individuals whose death dates are not observed are right-censored at their last day of observation, i.e. at birth or at

\footnotetext{
${ }^{5}$ See Mandemakers (2000) for further details of the sampling structure, goals of the HSN-database and more information on the HSN.

${ }^{6}$ The Netherlands, at the time, had 11 provinces and in terms of economic activity the three provinces included in this study were jointly very representative of the country. The same is true for aggregate mortality rates in our data which closely resemble patterns at the national level.
} 
Table 1: Sample sizes of three categories of individuals who reach age 16: those who die before marriage, those whose marriage and death date are observed, and those whose longevity is right-censored at marriage. Percentages by gender

\begin{tabular}{lcccc}
\hline \hline & $\begin{array}{c}\text { Number of } \\
\text { Individuals }\end{array}$ & $\begin{array}{c}\text { \% Never } \\
\text { Married }\end{array}$ & $\begin{array}{c}\text { \% Married- } \\
\text { Dead }\end{array}$ & $\begin{array}{c}\text { \% Married- } \\
\text { Censored }\end{array}$ \\
\hline Total & 5593 & 21.38 & 52.91 & 25.71 \\
Men & 2709 & 53.85 & 48.16 & 44.51 \\
Women & 2884 & 46.15 & 51.84 & 55.49 \\
\hline
\end{tabular}

marriage. As the legal age of marriage at the time was 16 years and the people who died before this age cannot contribute to the likelihood of marriage, these people are excluded from the model estimation. Further loss of observations owing to missing values of explanatory variables results in a final sample of 5593 individuals.

'Social class' is captured by a hierarchal index based on Van Tulder (1962)'s mapping from parental occupation into a six-layer (1 being the lowest and 6 the highest) hierarchical scale. ${ }^{7}$ This has been used in many other studies with the HSN data. In general, our observed explanatory variables for individual marriage and mortality are realized at birth as opposed to those acquired later in life, as the latter may be endogenous or confounded. The place of residence at birth is included as a binary choice urbanization indicator which takes a value of 1 if the person is born in a city and 0 otherwise. One disadvantage of the unprecedented observation window is the absence of several explanatory variables commonly used in the mortality literature but unobserved in population registers. Notably, we do not observe the individual's adult health status and access to public health services and medical technology.

To provide summary statistics of outcomes of interest, we distinguish between 3 types of people. The first group consists of people who never marry during their lifetime and therefore no marriage date is observed for them. The second group comprises of individuals for whom marriage as well as death dates are recorded. Those in the third category are not observed after their marriage and therefore their death dates are missing. Table 1 presents the sizes of the 3 groups and their composition in terms of gender.

Table 2 gives further details for these 3 groups of people, once again by gender, for the duration of marriage and mortality, where observed.

All births and most marriages in the data took place more than 50 years ago. This warrants some discussion. The relevance of studies with historical data for contemporary

\footnotetext{
${ }^{7}$ Examples of common 19th century occupations in Van Tulder's (1962) 6 social classes are as follows: (1) diker, day laborer, dock worker (2) beer brewer, farm laborer, florist, fisherman (3) barber, baker, shoe smith, carpenter (4) bailiff, merchant, innkeeper (5) factory manager, headmaster, infantry captain (6) lawyer, pharmacist, surgeon.
} 
long-run health effects of early-life conditions has been discussed extensively elsewhere (e.g. Van den Berg et al., 2011, and references therein). To the extent that early-life effects on marriage run through health between birth and marriage, these arguments also apply to the relevance of historical evidence of such effects. To assess the relevance of historical evidence of marriage effects, it is useful to cite some more information on the institution of marriage in Northwestern Europe within our observation window. Petersen (1960), Matthijs (2003), Hartman (2004) and Dribe and Lundh (2010) provide overviews, and the latter study also cites other recent overviews. In most of the 19th century, the average age at marriage was rather high, a substantial fraction of individuals remained bachelor, and the average age difference between men and women was about 2 years. These features are also visible in our data; see Table 2. Socio-economic origin, age, and geographical origin have been found to be particularly strong determinants of marriage choice. Perhaps more importantly for our purposes is the fact that many women left the labor force upon marriage, and instead bore children and took care of the household. In the absence of societal social safety nets, the economic and care dependence of spouses was high.

One may therefore expect that marriage was more important for survival than nowadays. Historical records also note a societal contempt for unmarried women beyond the age of 30 (Van Poppel, 1992). On the other hand, the association of marriage and childbirth means that women were exposed to life-threatening experiences during childbearing ages.

\section{$3 \quad$ Empirical methodology}

\subsection{Outline of the approach to identify causal effects}

Consider again Figure 1 in Section 1. We estimate a joint model for all four causal effects, taking into account that all variables may be affected by unobserved determinants. To deal with the potential endogeneity of the actual economic conditions in the household early in life, we use business cycle conditions in early years of life as an indicator of individual economic well-being. To explain how we deal with the endogeneity of marital status and the marriage date, it is useful to think of our data as containing two subsamples: one with individuals born in adverse years and one with individuals born in favorable years. Suppose that for each of these two subsamples, one can estimate the full model separately (this requires identification for given early-life conditions that are equal for all subsample members). The estimation would give two sets of results, including two different effects of marriage on mortality. Contrasting these results then reveals the effects of the indicator of early-life conditions on all parameters in the model, including the interaction effect of the indicator of 
Table 2: Summary statistics of duration variables

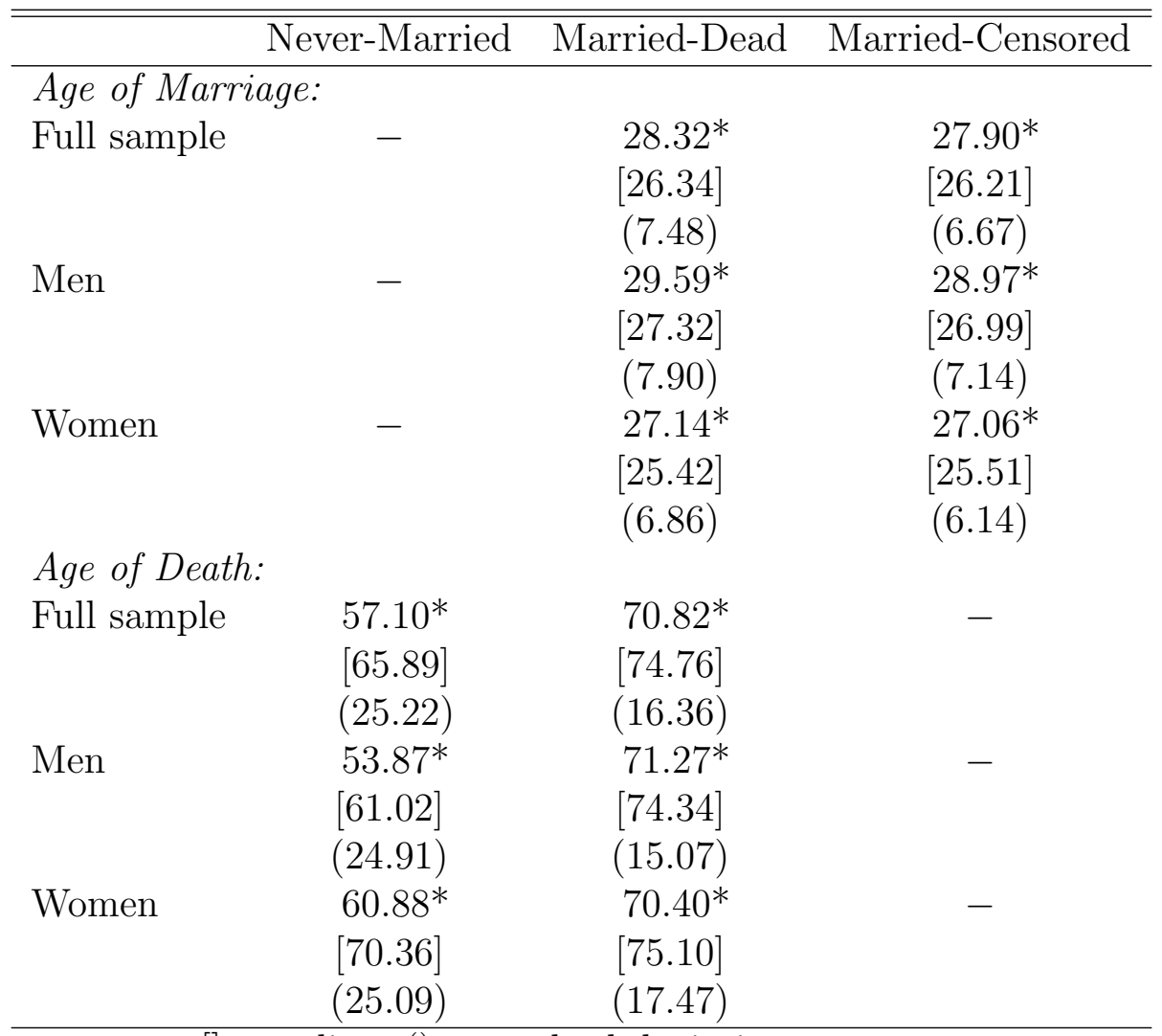

* : mean, [] : median, () : standard deviation

early-life conditions and the effect of marriage on mortality. ${ }^{8}$

What remains is to demonstrate that each of these two separate models is identified for given early-life conditions, even if the marriage date is endogenous in the sense that marriage and mortality have shared unobserved determinants. For this we rely on the Timing-ofEvents approach for the identification of the effect of the occurrence of one event on the rate that another event occurs (see Abbring and Van den Berg, 2003). In our context, the former event is marriage and the latter is death. For given early-life conditions, our model reduces to a bivariate duration model for the duration until marriage and the duration until death, with a causal effect of marriage on the mortality rate and with possibly shared unobserved determinants of the marriage rate and the mortality rate. The Timing-of-Events approach allows for the identification of such models, provided that (i) the unobservables are independent of the observed explanatory variables (i.e., the random effect assumption

\footnotetext{
${ }^{8}$ Notice that the empirical inference produces estimates of effects of the business-cycle indicator of earlylife conditions; not of the effects of the all early-life conditions themselves. The extent to which one can generalize the conclusions about the former effects to conclusions about the latter effects depends on the extent to which the cyclical fluctuations in economic conditions are collinear to the over-all actual conditions early in life. We return to this issue below.
} 
holds), and (ii) the marriage and mortality rates satisfy Mixed Proportional Hazard (MPH)type specifications. It is important to point out that for given conditions early in life, the identification of the marriage effect does not require an instrumental variable (in the usual sense of the word) for marriage. Identification effectively exploits the fact that the causal marriage effect on mortality only works from the entry into marriage onwards, whereas the association between marriage and mortality due to shared determinants works at all ages. This requires some amount of randomness in the moment of marriage, which in turn can be justified by the random element in the arrival of opportunities in the marriage market.

To disentangle the long-run effects of conditions at birth and during childhood, we may exploit the age variation in the timing of the stages of the business cycle across individuals.

The set-up of this section is as follows. In the next subsection we examine the businesscycle indicator of early-life conditions in detail. The subsequent subsection discusses the Timing-of-Events approach in detail.

\subsection{Business cycles}

In principle, one would like to compare cohorts born in economic booms to those born during economic troughs with otherwise identical conditions over life. This however is not possible due to the steady secular improvements in living conditions, medical innovations and health care over time. As Van den Berg et al. (2006) point out, this issue can be dealt with in a conservative way by comparing a cohort born in a specific boom to that born in the subsequent recession, because the latter benefit more from secular developments. In this case a reduction in longevity can be attributed to the cycle. However, given the small sample size of 5593 individuals, its impossible to compare outcomes from two consecutive stages of a cycle, especially if we wish to consider the two genders separately. Therefore, following Van den Berg et al. (2006) we identify intervals of successive years of "booms" and "recessions".

To obtain cyclical indicators, we decompose the historical time series on log annual real per capita GNP over the observation window. The GNP series, instead of the conventionally used GDP, is chosen purely for reasons of availability of mutually consistent observations over the years of interest. Due to the unavailability of GNP data for the years 1812-1814, we only consider individuals who were born in and after 1815. Figure 2 presents log annual real per capita GNP, measured in 1,000 Euros with 1995 as a base year. The graph highlights both the upward trend and the many cyclical fluctuations. ${ }^{9}$

We perform a trend/cycle decomposition of the log annual real per capital GNP using the Hodrick-Prescott filter with smoothing parameter 500. Figure 2 presents the cycle and trend of the GNP series as function of calendar time. The plot shows that periods of economic booms and recessions are clearly identifiable in the data and Van den Berg et al. (2006) show

\footnotetext{
${ }^{9}$ Jacobs and Smits (2001) discuss in detail the macro-economic time series in the Netherlands in the 19th century. Business cycles in the Netherlands were highly correlated to those in the United Kingdom.
} 


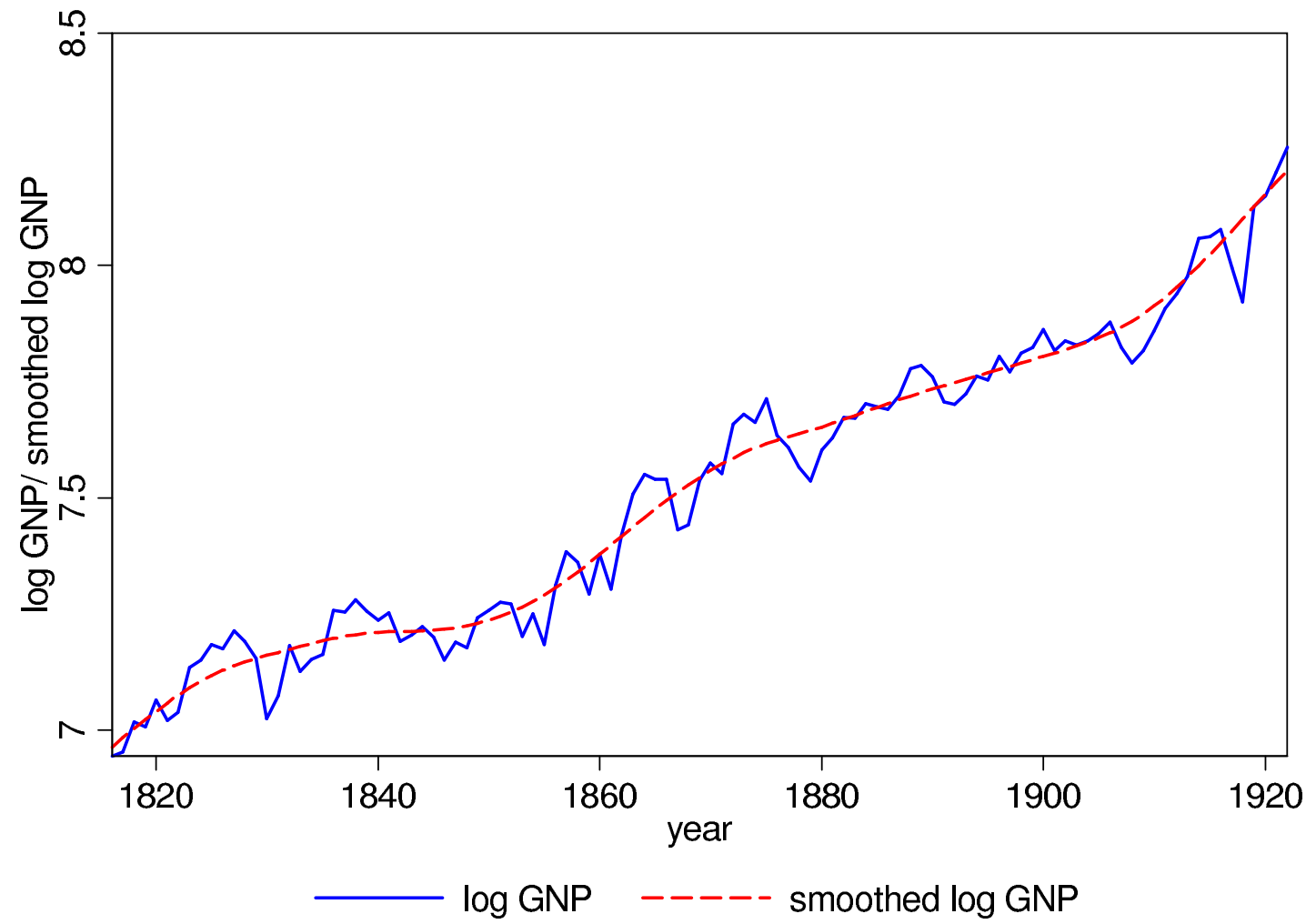

Figure 2: Log annual real per capita GNP.

that these are robust with respect to the choice of the decomposition method and smoothing parameter. Figure 3 provides a histogram of the distribution over time of the cyclical term (or indicator) which will be our main explanatory variable. For most of the analysis we round-off the value of the cyclical term to a binary outcome representing economic upturns or downturns.

We additionally control for incidence of epidemics ${ }^{10}$ and war. World War II (1940-45) has been the only war and occupation on Dutch soil since Napoleon. It included the severe famine of the winter of $1944 / 45$, where mortality rates peaked because of malnutrition (Jewish genocide victims were excluded from the data). The period of the World War II is represented using a separate dummy variable as no reliable macro-economic data is available for this interval.

For the interpretation of the results it is relevant whether the birth cohort size varies over the business cycle. Bengtsson and Dribe (2006) find that parents in rural Sweden in the 19th century fine-tune their fertility outcomes with respect to the anticipated fluctuations in the harvest returns. In our case, this would affect the availability of partners in the marriage market at the mean age of marriage, and this may affect the marriage rate in turn. Some past literature (for instance Blau et al., 2000) has found an inverse relationship between

\footnotetext{
${ }^{10}$ See e.g. Almond (2006) for discussion on adverse effects of in-utero exposure to an epidemic on long term individual outcomes.
} 


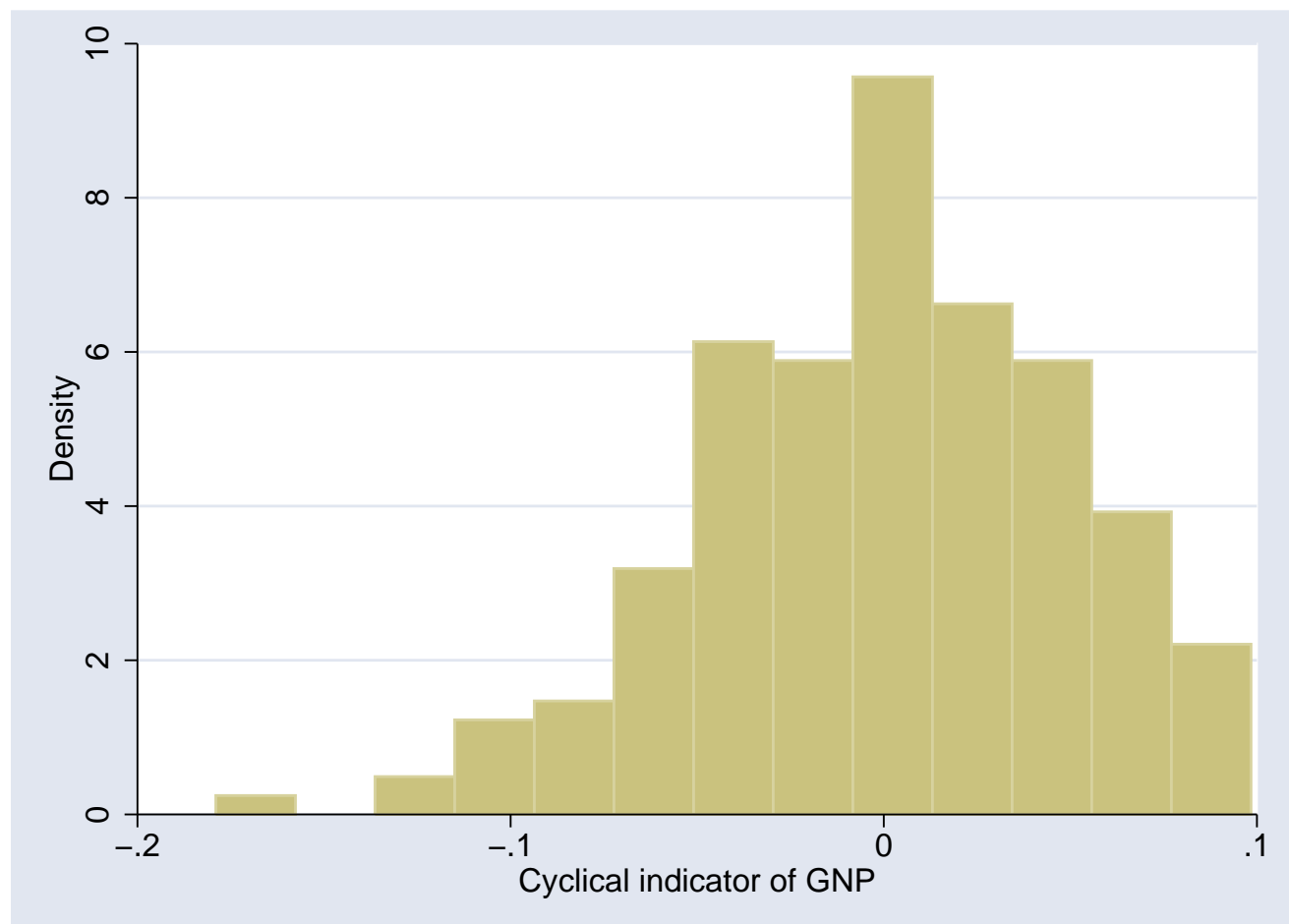

Figure 3: The distribution of the cyclical indicator of GNP over birth years.

contemporaneous marriage market tightness and marriage rates. In sum, if the cohort size is pro-cyclical then, following this line of reasoning, we would expect that the marriage rate in the cohort is also pro-cyclical. ${ }^{11}$ (At the same time, a large cohort size may suggest that relatively many frail individuals are born.) However, the availability of potential marriage partners at any point of time is also determined by contemporaneous economic conditions. And marriage markets depend on cohort sizes of men and women within certain age intervals of a size that is unknown to the researcher.

To proceed, we examine national time series of birth rates by gender. ${ }^{12}$ Regressing total births on the cyclical component of the GNP series, first in the year of birth and then separately in the year prior to birth, we find no significant correlations ${ }^{13}$ and hence little evidence of endogenous fertility. To get a closer look at the availability of potential marriage partners we consider sex-ratios over time and find that these remained pretty stable in the Netherlands at the time. Further, regressing sex-ratios on cyclical component of GNP series we find no significant correlation at age 0 or at age $16^{14}$. The information on ages of grooms and brides is only available for the province of Utrecht. Using this subset of the data, we find that the age difference between the groom and the bride is approximately normally distributed with the mean close to 2 years and a standard deviation of 5.84 years. Although

\footnotetext{
${ }^{11}$ Recall that an effect of the conditions at birth on the marriage rate by way of the health of the individual may go both ways: individuals born under adverse conditions may be less healthy and therefore have more difficulty in finding a partner, or these individuals are aware of higher benefits of marriage to mitigate a higher mortality rate and therefore have a higher marriage rate.

${ }^{12}$ Obtained for the whole of Netherlands from the Human Mortality Database (www.mortality.org).

${ }^{13} \mathrm{P}$-values of 0.37 and 0.84 respectively.

${ }^{14} \mathrm{p}$-value of 0.13 and 0.33 respectively.
} 
on an average the bride was younger than the groom, in the light of this distribution, the researcher is forced to make some assumptions about what comprises the potential pool of marriage partners. Considering the ratio of men to 2 year younger women, we find that this ratio also shows only little variation overtime. Finally, these findings continue to hold while studying the role of social class in determining marriage and mortality, which reiterates the findings of Van den Berg et al. (2009) who find no significant effect of cyclical components of the business cycle at birth on the over-all cohort size or the cohort size by social class. This is as far as we can go to address the issue whether the composition of newborns in terms of unobserved characteristics varies over the cycle.

\subsection{A bivariate duration model for marriage and mortality}

For convenience, we use lower case symbols for random variables as well as their realizations, and we abstract from potential outcome variables. The outcomes of interest are the duration until marriage $t_{m}$ and the duration up to death, $t_{d}$. We assume that all individual differences in the joint distribution of these two processes is conditional on calendar time $\tau$, other socioeconomic and demographic factors $x$, current macro-economic conditions $z(\tau)$, trend components and cyclical indicators $z_{t r}(\tau-t+i)$ and $z_{c}(\tau-t+i)$ of macro-economic conditions in earlier years of life $(i \in\{0, \ldots ., t-1\})$, various interaction terms, and the unobserved characteristics $v$. The vector $x$ contains covariates that are observable at birth, and $v$ is independent of $x$. Let $t_{m}$ be the moment at which an individual gets married. The indicator function $I\left(t_{m}<t\right)$ is used to denote whether an individual is married at age $t$ or not. The parameter $\delta$ captures the causal effect of marriage on the individual mortality rate. This parameter may in turn depend on various variables, including of course the early-life conditions. The studies mentioned in the previous sections suggest that the effect strongly depends on the age of the individual under consideration.

For ease of exposition, we may normalize $\tau$ for a given individual such that $\tau=0$ at birth, and we may subsume the variables $z(\tau), z_{t r}(\tau-t+i)$ and $z_{c}(\tau-t+i)$ in $x$, which accordingly becomes a time-varying explanatory variable $x(t)$. The unobserved determinants of the individual mortality rate and the marriage rate are denoted by $v_{d}$ and $v_{m}$, respectively. The mortality rate at age $t$, conditional on $x(t), v_{d}$, and $t_{m}$ is denoted by $\theta_{d}\left(t, x(t), v_{d}, t_{m}\right)$ and is assumed to have the following specification

$$
\theta_{d}\left(t, x(t), v_{d}, t_{m}\right)=\lambda_{d}(t) \exp \left(x^{\prime}(t) \beta_{d}+\delta I\left(t_{m}<t\right)+v_{d}\right)
$$

For $z(\tau)$ we take $\log$ annual real per capita GNP at $t$, as well as dummy variables for years with epidemics and World War II. ${ }^{15}$

Since the focus is on the impact of marriage on mortality, we only consider mortality after

\footnotetext{
${ }^{15}$ This takes care of the fact that GNP series is missing for the years of World War II.
} 
the age at which marriage becomes feasible i.e. the legal age of marriage of 16 years. We include information about the conditions prevailing in years of early childhood (1-5 years of age), leading right up to 16 years (ages between 6-12 and 13-15 years). These are summarized by 4 binary indicators. A binary boom / recession dummy is used to record a favorable (cyclical component $>0$ ) / adverse (cyclical component $<0$ ) period of the business cycle in the year of birth. 3 additional indicators of average cyclical macro-economic conditions during the age intervals of 1-5, 6-12 and 13-15 years are also included by means of dummies for whether or not the averages of the cyclical element of the GNP series is positive or negative between these ages.

The trend component $z_{t r}(\tau-t+i)$ of the GNP series in the years of birth and childhood, obtained from the Hodrick-Prescott decomposition, captures the secular long-run effects. Van den Berg et al. (2006) discuss in detail the empirical challenges in distinguishing the effects of these trend components from the effects of current $\log$ GNP $z(\tau)$ and age $t$, due to multicollinearity. All these variables are by and large increasing over time, and at the individual level current log GNP can be captured fairly well by the sum of the trend component of the GNP and an increasing function of age. Consequently the trend component is mostly omitted from the model specification. For similar reasons calendar time $\tau$ is also left out. The contemporaneous cyclical conditions in the macro-economy are also an indicator of current employment opportunities. Therefore inclusion of the cyclical component of the GNP would additionally control for the impact of on-going employment conditions which have been noted to influence the 'marriageability' of the individual (for instance Blau et al., 2000). The trend component of the series captures all secular effects from birth to the current age.

For an individual of age $t$ years who is not yet married, the marriage rate at $t$ conditional on observed and unobserved characteristics $x(t)$ and $v_{m}$ is denoted by $\theta_{m}\left(t \mid x(t), v_{m}\right)$ and is assumed to have the MPH specification given by,

$$
\theta_{m}\left(t \mid x(t), v_{m}\right)=\lambda_{m}(t) \exp \left(x^{\prime}(t) \beta_{m}+v_{m}\right)
$$

where once again $x(t)$ is independent of $v_{m}$ and the individual's background characteristics $x$ are constant over time.

Now consider the joint distribution of $t_{d}$ and $t_{m}$. Conditional on $x(t), v_{d}$ and $v_{m}$, the only possible relation between the variables $t_{d}$ and $t_{m}$ is the relation by way of the direct/ causal effect of a marriage on the mortality rate. In case of independence of $v_{d}$ and $v_{m}$, we would have a standard duration model for $t_{d} \mid x(t), t_{m}$ in which $I\left(t_{m}<t\right)$ can be treated as a time-varying regressor that is orthogonal to the unobserved heterogeneity term $v_{d}$. However, if $v_{d}$ and $v_{m}$ are not independent, inference on $t_{d} \mid x(t), t_{m}$ has to be based on $t_{d}, t_{m} \mid x(t)$. This means that we need to integrate the individual likelihood contribution over the distribution $\mathrm{G}\left(v_{d}, v_{m}\right)$ which is the joint distribution function of the unobserved characteristics $v_{d}$ and 
$v_{m}$ among 16 year olds. Right-censoring of individuals is solved in a straightforward manner within the duration analysis framework. We estimate the bivariate duration model with full maximum likelihood.

Strictly speaking, the effects of $z_{c}(\tau-t)$ in the model (including any effect on $\delta$ ) capture the causal effects of the business cycle at birth. We interpret the cycle at birth as an exogenous indicator of the early-life conditions. Suppose that the actual economic well-being of the parents' household at birth equals a permanent component plus a transitory component. If the permanent component is captured by social class and the transitory component equals a proportion of the business cycle indicator, then the quantitative effects of the business cycle indicator may be translated into quantitative effects of the actual economic conditions at birth.

\subsection{Parameterization}

We use flexible specifications for the causal effect $\delta$ of marriage on mortality rate, the duration dependence functions, and the bivariate unobserved heterogeneity distribution. In order to allow the causal effect of marriage on mortality $\delta$ to vary over the individual's lifetime, $\delta$ is expressed using Chebyshev polynomials, for instance of degree 4, in the age of the married individual. This polynomial could be specified simply as a sum of terms $\eta_{i} t^{i}, i=0,1, \ldots, 4$ where $t$ is the age of the individual. However, since the terms of $t^{i}$ are not orthogonal, estimation of the parameters $\eta_{i}$ is afflicted by multicollinearity. We take care of this problem by using Chebyshev polynomials of the second kind. In this case, the polynomial is specified as a sum of terms $\eta_{i} U_{i}(t), i=0,1, \ldots, 4$ where $U_{0}(t), U_{1}(t), U_{2}(t), U_{3}(t)$ and $U_{4}(t),{ }^{16}$ are mutually orthogonal polynomials of indexed degree. Furthermore, we allow this effect of marriage on the mortality rate to vary by conditions in early life of the individual by including interaction terms of $\delta$ and the dummy of being born in a boom or not as determinants of the mortality rate.

This set up implies that the total age dependent causal effect of marriage on the mortality rate for a married individual would be given by

$$
\delta=\sum_{i=0}^{4} \eta_{i}^{a p e} U_{i}(t)+\left(\sum_{i=0}^{4} \eta_{i}^{a, i n t} U_{i}(t) \cdot I_{b o o m}\right)
$$

where $\eta_{i}^{a p e}$ are the parameters corresponding to the mutually orthogonal polynomials $U_{i}(t)$ of degree $i$ capturing the age dependence of the causal effect of marriage on individual death rate. The second term $\left(\sum_{i=0}^{4} \eta_{i}^{a, i n t} U_{i}(t) \cdot I_{b o o m}\right)$ takes into account any effect of early-life

\footnotetext{
${ }^{16}$ To start, the domain of the ages $t$ where $t \in[0,103]$ is linearly transformed to the domain of the orthogonal Chebyshev polynomials such that now $\widehat{t} \in[-1,1]$. This is done in our case by using the simple rule $\widehat{t}=2 \frac{\left(t-t_{0}\right)}{\left(n_{t}-1\right)}-1$ where $n_{t}$ is the year of the individual's life that is being considered. Then our orthogonal polynomials are: $U_{0}(\widehat{t})=1, U_{1}(\widehat{t})=2 \widehat{t}, U_{2}(\widehat{t})=4 \widehat{t}^{2}-1, U_{3}(\widehat{t})=8 \widehat{t}^{3}-4 \widehat{t}, U_{4}(\widehat{t})=16 \widehat{t}^{4}-12 \widehat{t}^{2}+1$.
} 
conditions, represented by the dummy $\left(I_{\text {boom }}\right)$ for being born in a year of economic boom or not. The parameters $\eta_{i}^{a, i n t}$ are the coefficients of this interaction term. Consequently, for a person born during an economic recession $\left(I_{\text {boom }}=0\right)$ the total causal effect is

$$
\delta_{\text {recession }}=\sum_{i=0}^{4} \eta_{i}^{\text {ape }} U_{i}(t)
$$

The time dependence of the hazard functions is similarly expressed using Chebyshev polynomials of the second kind of degree 4 in age of the person. Thus, the duration dependence of the marriage and mortality rates are respectively given by:

$$
\lambda_{m}(t)=\exp \left[\sum_{i=0}^{4} \eta_{i}^{m} U_{i}(t)\right] \quad \text { and } \quad \lambda_{d}(t)=\exp \left[\sum_{i=0}^{4} \eta_{i}^{d} U_{i}(t)\right]
$$

These specifications contain 10 parameters in total $\left(\eta_{i}^{m}\right.$ and $\eta_{i}^{d}$, with $\left.i=0,1, \ldots, 4\right)$.

We take the joint distribution of the unobserved heterogeneity terms $v_{d}$ and $v_{m}$ to be bivariate discrete, with two unrestricted mass-point locations for each term. Let $v_{d}^{1}, v_{d}^{2}, v_{m}^{1}$, and $v_{m}^{2}$ denote the points of support of $v_{d}$ and $v_{m}$, respectively. The associated probabilities are denoted as follows:

$$
\begin{array}{ll}
\operatorname{Pr}\left(v_{d}=v_{d}^{1}, v_{m}=v_{m}^{1}\right)=q_{1}, & \operatorname{Pr}\left(v_{d}=v_{d}^{2}, v_{m}=v_{m}^{1}\right)=q_{3} \\
\operatorname{Pr}\left(v_{d}=v_{d}^{1}, v_{m}=v_{m}^{2}\right)=q_{2}, & \operatorname{Pr}\left(v_{d}=v_{d}^{2}, v_{m}=v_{m}^{2}\right)=q_{4}
\end{array}
$$

with $0 \leq q_{i} \leq 1$ for $i=1, \ldots ., 4$, and $q_{4}=1-q_{1}-q_{2}-q_{3}$.

The covariance of $v_{d}$ and $v_{m}$ is given by, $\operatorname{cov}\left(v_{d}, v_{m}\right)=\left(q_{1} q_{4}-q_{2} q_{3}\right) \cdot\left(v_{d}^{1}-v_{d}^{2}\right) \cdot\left(v_{m}^{1}-v_{m}^{2}\right)$. We note that $\operatorname{cov}\left(v_{d}, v_{m}\right)=0$ would imply independence of $v_{d}$ and $v_{m}$ and $q_{1}=q_{4}=0$ or $q_{2}=q_{3}=0$ would mean perfect correlation.

\section{Results}

\subsection{Estimation results by gender}

Table 3 presents the estimation results for the full model. For the estimates concerning entry into marriage, a positive value is associated with an earlier marriage. For the mortality rate, positive values of estimates signify a shorter lifetime.

The first crucial result is a significant causal effect of being married on the mortality rate for both men and women. Gender differences however are vital, and so are age and the conditions around the individual's birth. The estimates of the size of the effects of the latter are hard to read from the separate coefficients in Table 3. Figure 4 therefore presents the impact of marriage on the instantaneous mortality rate by gender and also separately for birth during an economic boom versus a recession. For sake of exposition, the instantaneous 
hazard rates are plotted for marriage at the age of 30. Similar results (not presented) are obtained for other ages of marriage. The figures also plot the mortality rates in the absence of marriage. To show the effect of marriage without 'contamination' from other explanatory variables, each panel averages over the other explanatory variables. Note however that the model includes a time-varying explanatory variable (GNP trend) whose effect runs against the age dependence of the mortality rate. Therefore, care should be taken when interpreting the increasing shapes of the mortality rates in the figure.

The four panels of Figure 4 clearly show a sudden jump in the mortality rates at the moment of marriage. For women born in a recession, the mortality rate shows a large and long lasting increase in response to marriage. Favorable early life conditions help mitigate the adverse effect of marriage for women. For men, on the other hand, the impact of marriage on the mortality rate is favorable irrespective of cyclical conditions pertaining in the economy at the time of birth. This result goes against the view that there is no protective effect of marriage for women. Instead, the degree of protection depends on early-life conditions and changes with age. In any case, part of the association of marriage and life expectancy is causal for each gender.

We aim to determine whether the causal effect of marriage on mortality is statistically significant or not. Figure 5 displays the estimates of the age-dependent marriage effect interacted with the indicator of early-life conditions on mortality, along with the $95 \%$ confidence intervals, on the $\log$ mortality rate (that is, $\delta$ is plotted rather than $\exp \delta$ ). Once again, given large gender differences and the vital role of the economic conditions in early years of life, the plots are presented separately by gender and condition of the business cycle in the birth year. The results reiterate the presence of an age-dependent causal effect of marriage on mortality for both genders and the relevance of the early life conditions as suggested by the analysis of the instantaneous mortality rate around the time of marriage. We proceed to discuss the results for women and after that for men.

For women (Figure 5a) we find that marriage instantaneously significantly raises the mortality rate in the childbearing ages. This adverse effect of marriage is much stronger - and persists for a longer time - in case of birth under adverse economic conditions. So women born in favorable economic times appear to cope better with problems during the childbearing ages than women born in a year of recession. (in Subsection 4.3 we provide the implied quantitative estimates of average effects on longevity).

It is plausible that the increased mortality during childbearing ages, as compared to the mortality when being single, reflects the health hazards of pregnancy, delivery, childbearing, and taking care of small children. Indeed, in the absence of advanced contraceptives, pregnancies would follow soon after marriage. Additional risk factors for married women in childbearing ages are (i) a possible reduction of nutrition upon the arrival of children, as the total available amount needs to be shared among a larger number of household members, 

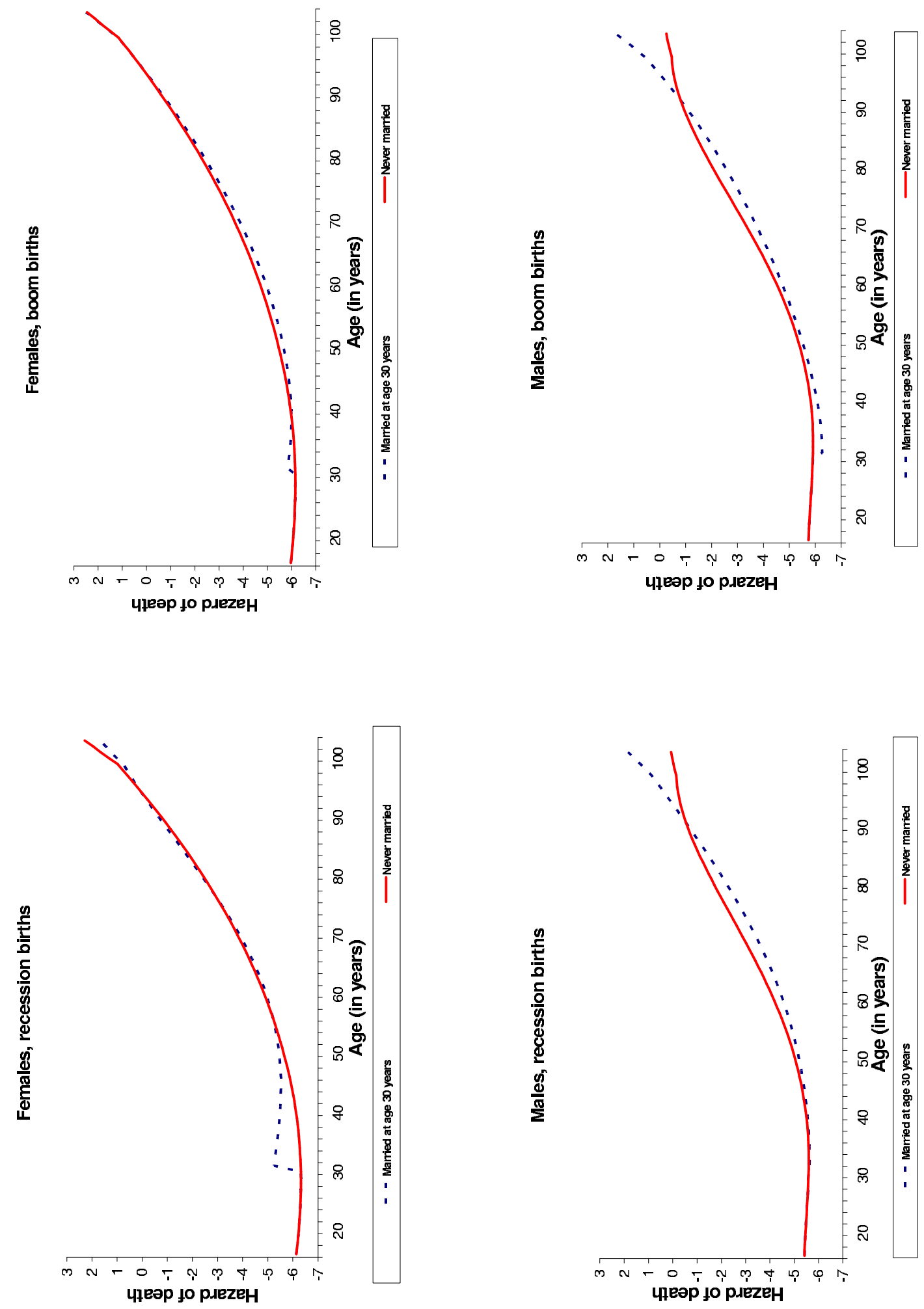

Figure 4: Impact of marriage at age 30 on mortality rate, by gender and by state of the business cycle at birth. 


\section{Females, recession births}

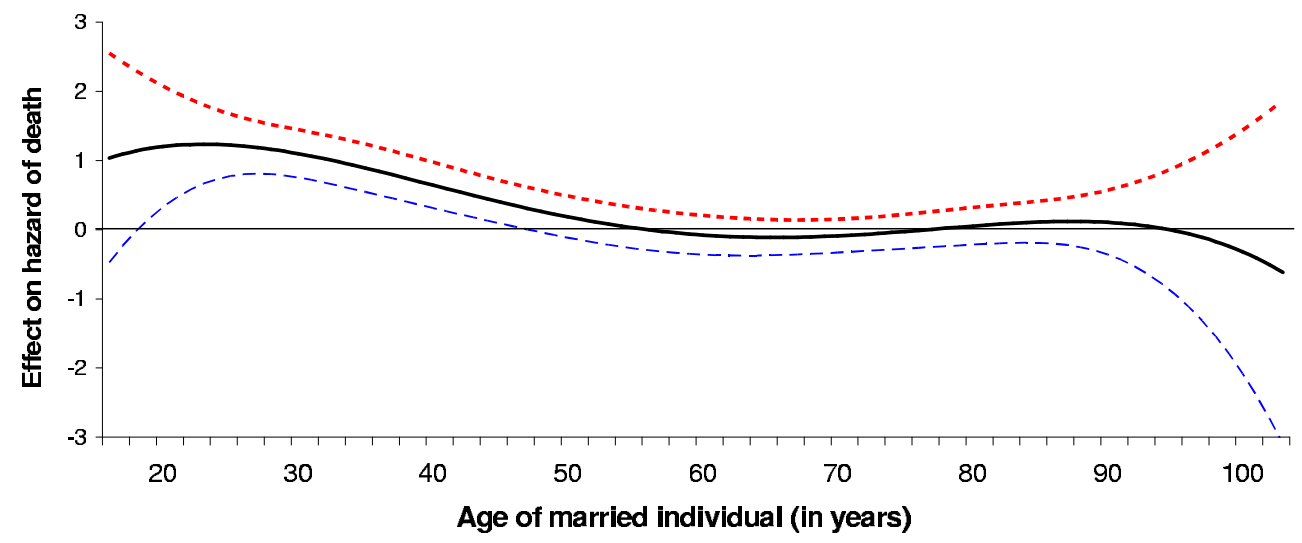

-Age dependent causal effect of marriage - - - Lower confidence interval (95\%) - - - Upper confidence interval (95\%)

Females, boom births

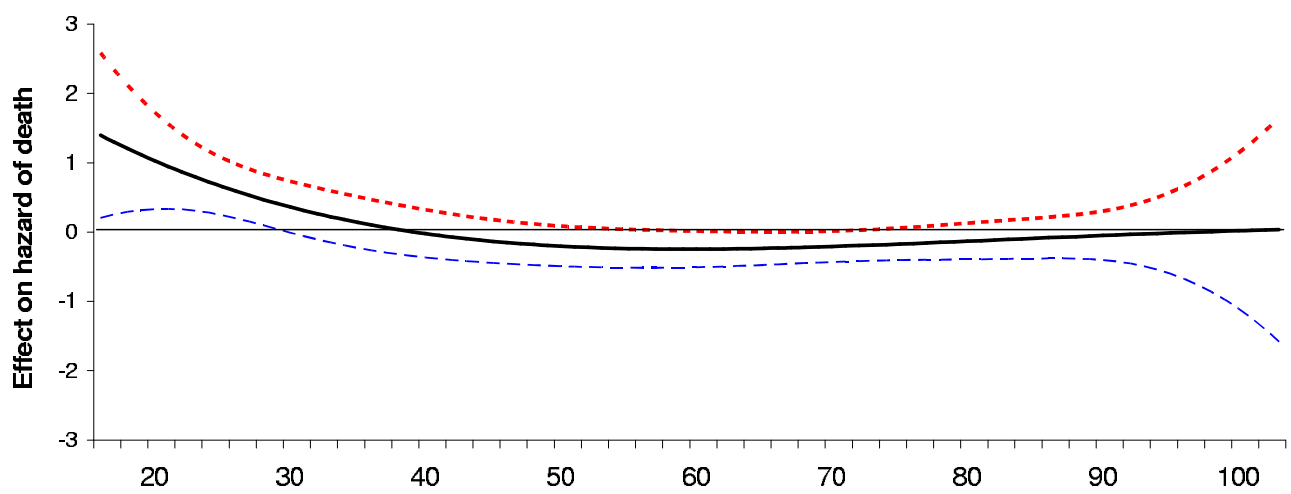

—Age and Age $x$ dummy for bom in boom - - - Lower confidence interval (95\%) - - Upper confidence interval (95\%)

Figure 5: (a) Causal effect of marriage on the mortality rate interacted with economic conditions at birth, as a function of age, for women. 
Males, recession births

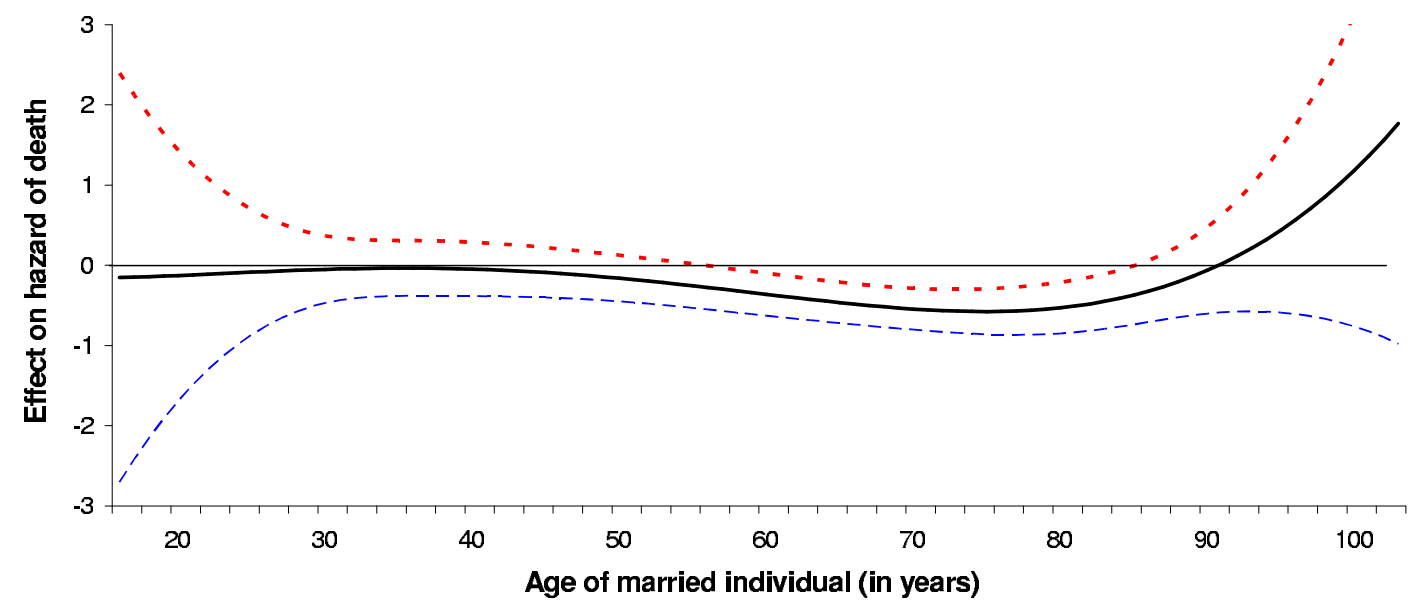

- Age dependent causal effect of marriage $\quad$ - - - Lower confidence interval $(95 \%) \quad$ - - - Upper confidence interval $(95 \%)$

Males, boom births

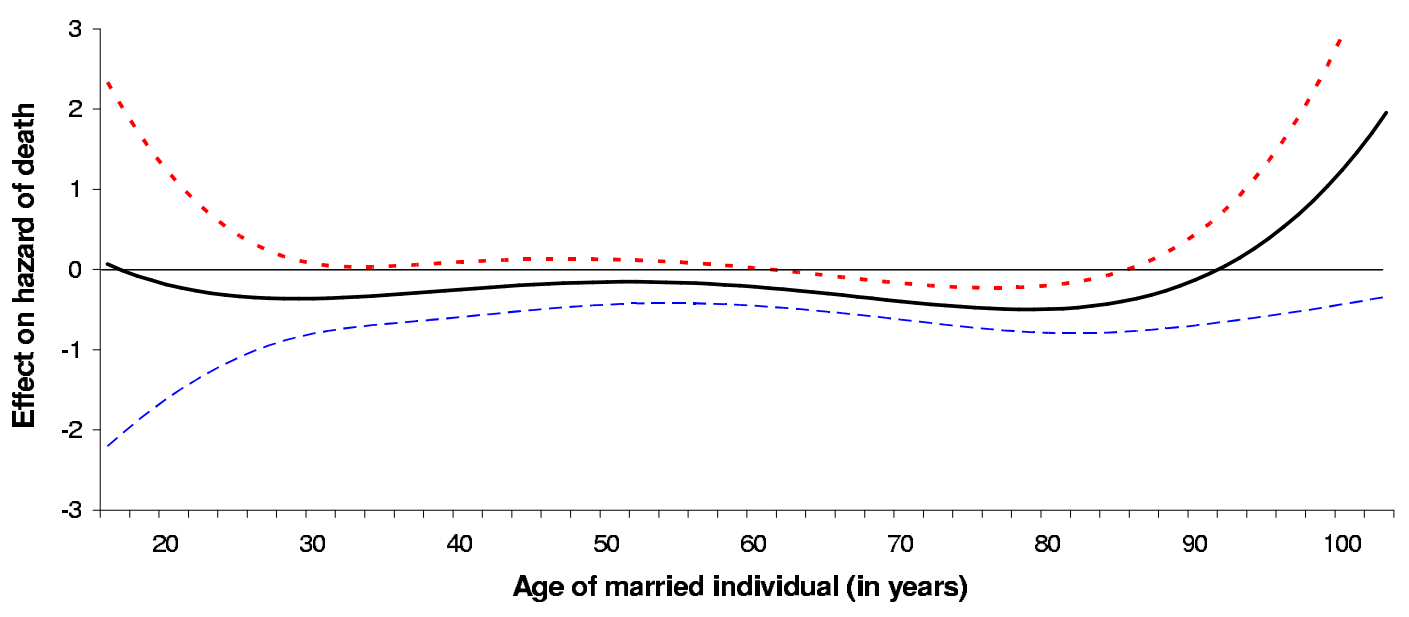

_ Age and Age $x$ dummy for born in boom - - - Lower confidence interval (95\%) - - - Upper confidence interval (95\%)

Figure 5: (b) Causal effect of marriage on the mortality rate interacted with economic conditions at birth, as a function of age, for men. 
and (ii) an increased exposure to infectious diseases brought into the household by small children. Investigation into the precise driving forces would require data on causes of death (for instance during childbirth). Maternal mortality (i.e., mortality at birth of a child) statistics are unavailable for the Netherlands for our observation window. However, studies report figures of maternal mortality in pre-industrial western societies ranging up to 1600 deaths per 100,000 live births (De Brouwere et al., 1998). Maternal mortality rates in the Netherlands can be expected to be similar to those of Sweden (250-300) and England and Wales (400-450) around 1870. Results from studies on trends in age and gender specific mortality declines in the Netherlands (for e.g. Wolleswinkel-van den Bosch et al., 1998) find a decline in female mortality towards the end of our observation window for the age interval of 20-49. The authors link this to a decline in marital fertility that started around the same time.

Our results are then consistent with the view that early-life conditions influence the resilience of women during the childbearing stage of the life course. For lack of data, the epidemiological literature has not addressed the effect of early-life conditions on the female mortality associated with pregnancy and delivery. However, a number of studies have demonstrated early-life effects on pregnancy complications and poor reproductive success, where the data are collected retrospectively among those who survive the delivery of their children. Lumey and Stein (1997) show that among women who had been exposed to a famine in utero and who survived up to age 43, the offspring was more likely to suffer from perinatal death. Innes et al. (1999), using birth weight as a proxy for early-life conditions, observe an effect of low birth weight on the risk of developing preeclampsia during pregnancy. The latter is a potentially deadly condition. Hackman et al. (1983) find an inverse association between the mother's birth weight and the baby's need for intensive care. See also the surveys by Lummaa (2003) and Sloboda et al. (2011). The latter reports that women with low birth weight show a marked reduction in ovarian and uterine size in adolescence. Under the assumption that neonatal health problems for the offspring and maternal health problems during childbirth may have common determinants, these studies are of relevance for us. Specifically, they reinforce our interpretation of the role of early-life conditions on health during the childbearing stage of the life course.

Potentially, our empirical finding that early-life conditions influence the length of the age interval during which marriage is not protective against mortality could also be attributed to an effect of early-life conditions on the length of the fertility age interval (age at menopause minus age at menarche). However, according to the epidemiological literature, there is no clear association between nutritional conditions early in life and the size of this interval or on the age at menopause (see Sloboda et al., 2011, for a survey).

Notice that the long-run effect of early-life conditions on female mortality is entirely driven through marriage, in the following sense. Early-life conditions affect the extent to which marriage is protective for mortality. However, they do not affect the mortality rate if 
marriage does not take place in one's lifetime.

At the same time, female marriage rates are unaffected by conditions in the years of birth and early childhood (early childhood being ages 1-5 years, which the medical literature identifies as crucial for long term development; see e.g. Power et al., 2003). This shows that any strategic considerations to enter or postpone marriage in response to favorable or adverse economic conditions early in life do not play a major role as determinants of marriage. At the very least, any such behavior does not result in visible effects on the marriage rates. Interestingly, the aforementioned study of Lumey and Stein (1997) finds that age at first delivery does not depend on whether the woman was in utero during a famine or not.

Turning now to men (Figure 5b), we find a protective causal impact of marriage on the mortality rate. The effect is significant over the typical ages at death of about 56-85. This finding is intuitive in light of social observations like growing loneliness owing to shrinking social circles for single individuals. Marriage on the other hand could offer support from a wife during older ages and improve quality of life by means of better housekeeping and personal care. The HSN does not record the time of death of spouses of the individuals in the sample. The absence of a consistently positive protective effect of marriage beyond the ages of 85 years probably reflects a limitation of our polynomial specification.

As for the role of conditions in early years of life, in contrast to women, for men we find no significant effect of being born in a boom as opposed to being born in a recession on the protective effect of marriage on the mortality rate. Though men born during adverse economic conditions seem to be enjoying the positive marital effect for marginally longer than married men born during favorable conditions, this difference is not statistically significant. Of course, men born under favorable conditions live on average longer (we discuss this in the next paragraph). Finally, for both men and women our results again show that marital status does not have a time constant impact on the mortality rate throughout life.

Considering the direct impact of early life conditions on mortality, we find a significantly lower mortality rate amongst men born during a boom. This reiterates the results of Van den Berg et al. (2006) who estimate mortality models without including marital status as an explanatory or intermediate variable. Another striking result is a significant negative effect of average cyclical conditions during the age interval of 7-12 years on the marriage as well as the mortality rate of men. We postulate two explanations for this. The first one concerns education. The age interval 6-12 coincided with primary school in the Netherlands, which prior to 1901 was not compulsory and only free for the very poor. Many individuals did not get more formal education than this. Better economic conditions at these ages could facilitate the entry into secondary education; moreover it could lead to larger professional involvement and consequent delays in marriage. In recessions, financial adversity could increase temporary absences from school affecting negatively at least the 'quality' of education (Dunn et al., 2003). 
Better educational opportunities could also explain the significant negative impact of favorable conditions at ages 7-12 on male mortality. Studies such as Cutler and Lleras-Muney (2006) and Maccini and Yang (2009) find a mediating effect of education on the mortality rate. The fact that we do not find a significant effect of average cyclical conditions during the age interval of 7-12 years on the marriage and mortality rates for women is not inconsistent with this. School attendance was often lower and shorter than for men, and career concerns were mostly absent.

The second explanation, which is especially relevant for the direct effect of conditions at ages 7-12 on male mortality, is that these ages include a critical or sensitive period in boys' development towards their adult health status. Specifically, Van den Berg et al. (2010) identify such a period at around age 9 in the sense that if conditions at this age are adverse then adult height is lower.

Class differences are very important for nuptiality. Male members of the three lower social classes exhibit a much larger marriage rate relative to the upper classes. This is in line with past observations of more frequent and younger marriages for the lower social classes resulting from increased economic opportunities following the industrial revolution (see the literature mentioned in Section 2). Possibilities of social class upward mobility by means of marriage may also arise for women. Investigation into marriage market prospects is left to future work.

Finally, considering age dependence of exit rates into marriage and mortality we find the expected inverted U-shape for the former and a monotonically increasing one for the latter (see Figure 6). We observe that the marriage rate increases till the age of 32 for men and 29 for women after which it consistently declines though at a slower rate after the mid 40's. This sudden slow-down in the declining marriage rate could indicate second marriages. However, in the absence of information about multiple marriages and continued marital status of individuals we are unable to comment any further.

\subsection{Sensitivity analysis}

\subsubsection{Other specifications for the marriage effect on mortality}

As robustness checks we estimate several alternative specifications of the causal effect of marriage on the individual mortality rate. First, we try a simpler model with only the age dependent marital effect on mortality without the interactions with the dummy for being born in a boom or not. Another specification replaces the age of the married individual with the number of years married as a determinant of the causal effect of marriage on mortality. This specification is tested with and without additional interaction terms between early life conditions and the number of years married. Finally, following past literature we estimate a 'basic' model where the causal effect of marriage is specified as a time varying regressor i.e. 

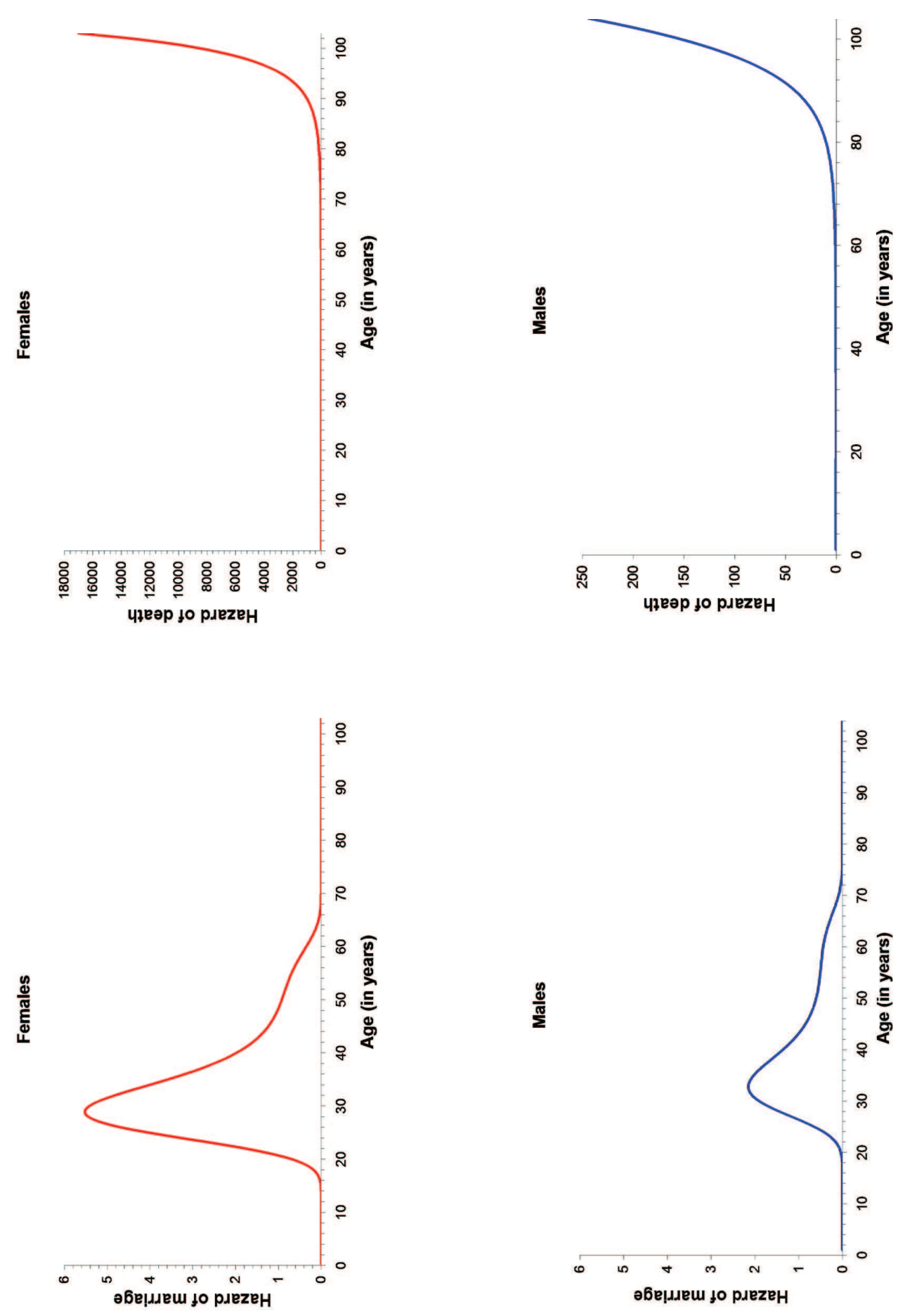

Figure 6: Age dependence of marriage and death (baselines) by gender. 
takes a value of 0 before the person is married and 1 after his marriage. Our results are robust to all these alternative specifications. Tests confirm that our full model as estimated above is a better model specification. For sake of brevity, detailed discussion of these alternative specifications and full parameter estimates are not presented here but can be requested from the authors.

\subsubsection{Alternative specifications of other explanatory variables}

Different specifications were also tried for other independent variables. Without presenting the detailed parameter estimates of these alternative specifications, this subsection briefly discusses the distinctive features of each of these options. Given our interest in the impact of early conditions in life on marital and mortality outcomes later in adult life we start by giving a closer look to our indicators of early life conditions. First, instead of our 4 binary indicators of early life conditions - birth in a year of economic boom and average cyclical macroeconomic conditions during the ages of 1-6, 7-12 and 13-15 years - we re-estimated our model of marriage and mortality using the actual, average values of the cyclical component of the GNP series at birth or during these age intervals. Our results are robust to this variation. We also tried alternative age intervals for our average cyclical indicators and once again our results remain unchanged. Irrespective of the choice of the intervals the average cyclical conditions during the ages covering the years 7-12 continue to be influential in the marital and death outcomes for men. Distinguishing between the effect of an economic boom around the time of entering primary school and that closer to finishing primary schooling could help shed further light on potential channels underlying the results we observe. Unfortunately our data does not record school enrollment for the subjects and moreover since schooling was neither mandatory nor essentially starting at a fixed age we are unable to comment any further on the possible underlying mechanisms.

\subsubsection{The relevance of early conditions in life for the model fit}

In the light of past literature that focuses on adult health as a determinant of individual marriage and mortality rates we try to assess the value added by these early life conditions in our estimation. We do so by re-estimating our models without controlling for economic conditions and exposure to epidemics during childhood and years of adolescence. For women, we compare our model with interactions between early life conditions and an age dependent causal effect of marriage to a simpler model with just an age dependent causal effect of marriage on mortality without any controls for early conditions in life. We note that the latter is nested in the former and a likelihood ratio (LR) test rejects the smaller model ${ }^{17}$. Similarly

\footnotetext{
${ }^{17} \mathrm{LR}$ statistic for the full model vs. the model with age dependent causal effect on marriage without controls for early conditions in life, 41.96 for women with a $\chi^{2}(20), 5 \%$ critical value 31.41 .
} 
for men for whom early life conditions did not significantly interact with the causal effect of marriage on the mortality rate, the direct contribution of cyclical economic conditions in first years of life on later life mortality is highly relevant. ${ }^{18}$ From this experiment we conclude that early life conditions are an important determinant of individual marriage and mortality later in life. This result provides support to the hypothesis that the link between marital status and mortality is to some extent driven by conditions in the early years of an individual's life.

\subsection{Additional discussion and implications}

Using our parameter estimates in Table 3 and the actual ages of marriage of the individuals in the sample we find that on an average ${ }^{19}$ marriage implies a $2.16 \%$ decrease in longevity for women. However, once we control for business cycle conditions in the year of birth these figures look very different. For women born during an economic boom, marriage in fact has favorable impact on their life expectancy ( $0.61 \%$ increase in expected lifetime). Therefore, the result of an adverse effect of marriage on the mortality rate for women aged less than 52 years is driven only by women born during economic downswings. For this group marriage reduces expected longevity by $5.40 \%$. For men, marriage leads to a $4.77 \%$ increase in life expectancy on an average with no significant difference between those born during economic boom versus births during economic recessions.

Given the non-constant protective effect of marriage over an individuals lifetime, it is also useful to consider by how much life expectancy changes if you marry at any given age. Figure 7 presents the change in life expectancy as a consequence of marriage for every possible age of being married (16 -103 years), calculated using the parameter estimates from our model and averaging over all other explanatory variables. Results are once again presented separately by gender and economic boom or not in the year of birth. Getting married at young ages (below about 25 years) shortens longevity regardless of early-life conditions, as compared to staying single. This is most likely because marriage at young ages increases the length of the childbearing age interval. The adverse effect reduces with increasing age at marriage. Married teenagers are in the worst position. Beyond the mid twenties the adverse effect of marriage on longevity only holds for women born in recessions. This finding suggests that women who might have already suffered a health set-back early in life are less able to cope with future health strains. For men on the other hand, the protective effect is generally higher the younger they marry. We cannot identify the reasons for this result from the data we have. However, early on set of healthier lifestyle and safe habits are plausible causes.

\footnotetext{
${ }^{18} \mathrm{LR}$ statistic for model with age dependent causal effect of marriage on the mortality rate and direct controls of early life conditions vs. model with age dependent causal effect on marriage without controls for early conditions in life, 57.23 for men with a $\chi^{2}(20), 5 \%$ critical value 31.41 .

${ }^{19}$ Averaging over individuals marrying at various ages.
} 
Finally, once again we see that the role of early life conditions via marriage is less relevant for men.

The presence of adverse health consequences of marriage for women raises the question why women choose marriage, especially since decisions involve expected present values of various options, and any long-run benefits of marriage are discounted more heavily than the short-run costs. A similar concern has arisen in the "family pay gap" literature that finds large wage penalties for women choosing to have children. It appears that not only do women planning to have children self select themselves into lower earning occupations and jobs, they also accept large wage losses on return to labor market after child-related employment breaks (see e.g. Beblo et al., 2006). Recent social-psychological literature on female well-being provides some insight into the forces driving these choices. Abele-Brehm in a recent study using longitudinal data on about 2000 individuals finds higher levels of "life satisfaction" amongst women living with partners, with women on maternal leave being especially satisfied. This field of research seems to indicate that while women pay a large cost in terms of income and even health by choosing to have a family, family life is crucially important for their "happiness" making having a family the preferred choice for a lot of women. Wong (2007) structurally estimates an equilibrium matching model of the marriage market and the labor market, and she concludes that women derive a large non-pecuniary utility flow from being married and having children. Without such non-pecuniary utility, the fit of the model is significantly worse. Of course, evolutionary theory provides a more fundamental explanation for why women prefer to engage in an institution such as marriage that provides a setting within which to obtain and raise offspring.

Several obvious similarities exist between 19th century Dutch society and the current-day developing world. Therefore results drawn from this study could help policy makers in less developed economies in their struggle against child deprivation and high mortality rates (see De Brouwere et al., 1998). Supporting children born in adverse economic times, by means of extra provisions of food, housing and health care, will not only help decrease infant and child mortality but in fact increase over all male life expectancy. Special care could be taken in supporting female children born in economic downturns for whom health consequences of adverse early economic conditions are indirect (via marriage) and not immediately visible. In societies where the girl child is frequently considered only secondary to her male siblings, in absence of immediate consequences of female child deprivation, her needs are likely to be easily ignored during poor economic times leading to life long adverse health consequences. Further support could be provided to women during their child bearing ages. This could be done by discouraging marriages of very young women especially in rural areas or within lower social classes and religious communities by setting and enforcing suitable legal age of marriage. Additionally, access to modern contraceptives could help curb quick successive pregnancies that lead to high infant and maternal mortality rates. Active family planning 

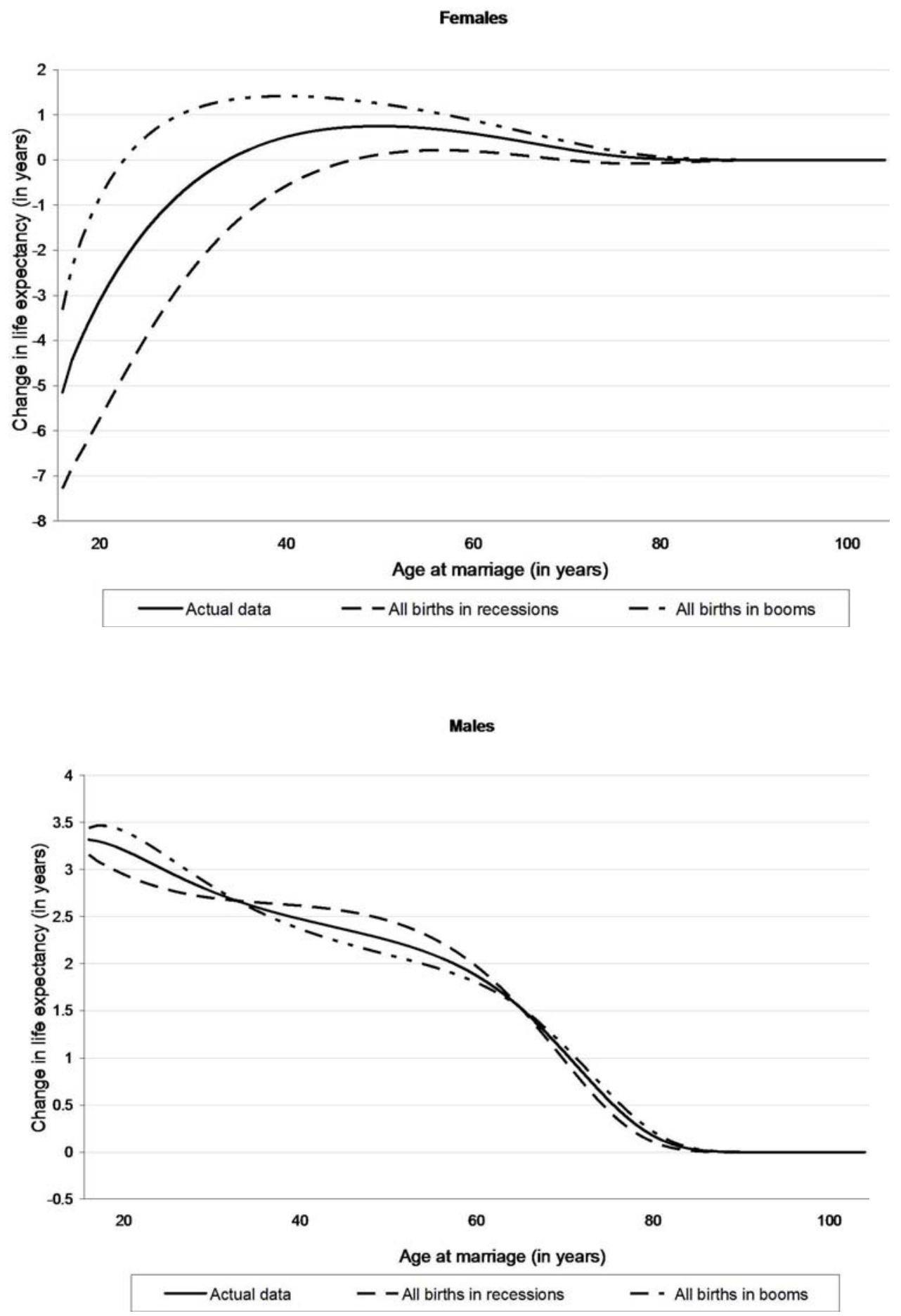

Figure 7: Expected changes in life expectancy as a causal effect of marriage at different ages of getting married. 
programs could also allow couples to enjoy the benefits of partnership without suffering from its negative health consequences. Over a longer time horizon, urbanization, economic development of the country (reflected in high per capital real GNP) and more education would help discourage early marriages and consequently its adverse consequences, especially for women.

In future work it would be interesting to consider other (and possibly multiple) marital transitions like - divorced, separated, widowed etc. for each individual. This would provide more precise results about the protective effect of marriage under weaker assumptions (i.e.v could be allowed to be dependent on $x$ ). It would be also useful to have a closer look at the impact of social class on individual exits into matrimony or death. Although we controlled for social class using a linear, hierarchal indicator, we are unable to study each of the classes separately due to small sample sizes. A larger data set would help facilitate such an analysis. On a slightly different front, it would be interesting to study marriage market tightness as a determinant of the marriage rate by social classes, gender, degree of urbanization of place of residence and age. For this we would need to merge the HSN with marital life tables for the Netherlands for our observation window.

In future research it would be useful to have data records that include observations of the timing of childbirths and the attained level of education. This would enable a somewhat more direct assessment of the mechanisms that we postulate to drive the causal pathways we find. For example, we could allow the causal effect of marriage on mortality to depend on the moments of childbirths. Barring data on education, it would also be interesting to allow the causal effect of marriage on male mortality to depend on additional indicators, like the state of the business cycle at ages 7 to 12 .

\section{Conclusion}

The empirical analyses in this paper generate a range of insights into causal pathways between economic conditions early in life, marriage, and mortality. These are identified while taking account of selection effects due to unobserved confounders. The results are markedly different between men and women.

For women, the extent to which marriage protects against mortality depends on the economic conditions early in life. Birth under adverse conditions implies that longevity is reduced upon marriage, as compared to staying unmarried. Conversely, birth under favorable conditions implies that longevity is extended upon marriage. In each case, the effect of marital status on mortality is not uniform as a function of age. The health costs of marriage are borne early on, whereas the protective benefits occur after the childbearing ages. But for women born under favorable conditions, the costs during childbearing ages are smaller, and the age at which benefits outweigh costs occurs earlier in life. 
We provide a range of reasons for why the health costs of marriage during childbearing ages are due to the health hazards of pregnancy, delivery, childbearing, and taking care of small children. Our results are consistent with the view that early-life conditions influence the resilience of women during this stage of the life course. In current times, in Western societies, maternal death during deliveries and during childbearing ages in general is very rare. However, it is plausible that the various stages of childbearing are still a health burden for the mother, and it is obviously useful to know that this burden is larger in case the mother was exposed to adverse conditions in her own birth year.

The analysis for women also shows that early-life conditions do not influence the marriage rate. This shows that strategic considerations to enter or postpone marriage in response to favorable or adverse economic conditions early in life do not play a major role as determinants of marriage. The decision to marry is driven by other behavioral motivations.

For men the results are different. Marriage is protective at all ages, and the size of the protective effect on the mortality rate does not depend on conditions early in life. At the same time, conditions around birth have an autonomous long-run effect on mortality. For men, conditions around the ages 7 to 12 are important for the marriage rate as well as the mortality rate. Presumably, these are the ages in our sample during which decisions are made regarding education and career. Favorable conditions at these ages lead to a postponement of marriage and to lower mortality later in life.

The long-run causal pathway from early-life economic conditions to mortality late in life differs by gender. For women, the long-run effect is driven through marriage. Early-life conditions affect the extent to which marriage is protective for mortality. However, they do not affect the mortality rate if marriage does not take place in one's lifetime. For men, the long-run effect is present regardless of the marital status during one's adult life. Its size is not affected by marriage. 


\section{References}

Abbring, Jaap H. and Van den Berg, Gerard J. (2003), The non-parametric identification of treatment effects in duration models, Econometrica, Vol. 71, pp.1491-1517.

Abele-Brehm, Andrea (2006), Who is happiest? Career and family as determinants of professionals' life satisfaction in the "Life Rush Hour" between thirty and forty: Findings from the Erlangen longitudinal study.

Almond, Douglas (2006), Is the 1918 Influenza Pandemic Over? Long-Term Effects of In Utero Influenza Exposure in the Post-1940 U.S. Population, Journal of Political Economy, Vol. 114(4), pp. 672-712.

Beblo, Miriam; Bender, Stefan and Wolf, Elke (2006), The wage effects of entering motherhood - a within-firm matching approach, ZEW Discussion Paper No. 06-053.

Bengtsson, Tommy and Dribe, Martin (2006), Deliberate Control in a Natural Fertility Population: Southern Sweden, 1766-1864, Demography, 43(4), pp. 727-746.

Blau, Francine D.; Kahn, Lawrence M. and Waldfogel, Jane (2000), Understanding Young Women's Marriage Decisions: The Role of Labor and Marriage Market Conditions, Industrial and labor Relations Review, Vol. 53, pp. 624-647.

Case, Anne; Fertig, Angela; and Paxson, Christina (2003), From cradle to grave? The lasting impact of childhood health and circumstance, Working paper, NBER and Princeton University.

Cutler, David M. and Lleras-Muney, Adriana (2006), Education and Health: Evaluating Theories and Evidence, NBER Working Papers 12352, National Bureau of Economic Research, Inc.

De Brouwere, Vincent; Tonglet, René and Van Lerberghe, Wim (1998), Strategies for reducing maternal mortality in developing countries: what can we learn from the history of the industrialized West?, Tropical Medicine 6 International Health, Vol. 3 (10), pp. 771-782.

Doblhammer, Gabriele (2004), The late life legacy of very early life, Springer, Berlin.

Dribe, Martin, and Lundh, Christer (2010), Marriage choices and social reproduction: The interrelationship between partner selection and intergenerational socioeconomic mobility in 19th-century Sweden, Demographic Research, Vol. 22, pp. 347-382.

Gardner, Jonathan; and Oswald, Andrew J. (2004), How is mortality affected by Money, Marriage and Stress?", Journal of Health Economics, Vol. 23(6), pp. 1181-1207.

Goldman, Noreen (1993a), Marriage selection and mortality patterns: inferences and fallacies, Demography, Vol. 30, pp. 189-208. 
(1993b), The perils of single life in contemporary Japan, Journal of Marriage and the Family, Vol. 55, pp. 191-204.

Hackman, Evette, Emanuel, Irvin, Van Belle, Gerald; and Daling, Janet (1983), Maternal birth weight and subsequent pregnancy outcome, Journal of the American Medical Association, Vol. 250, pp. 2016-2019.

Hartman, Mary S. (2004), The Household and the Making of History: A Subversive View of the Western Past, Cambridge University Press, Cambridge.

Hu, Yuanreng; and Goldman, Noreen (1990), Mortality differentials by marital status: An international comparison, Demography, Vol. 27, pp. 233-50.

Innes, Kim E., Marshall, Julie A., Byers, Tim E.; and Calonge, Ned (1999), A woman's own birth weight and gestational age predict her later risk of developing preeclampsia, a precursor of chronic disease, Epidemiology, Vol. 10, pp. 153-160.

Jacobs, Jan and Smits, Jan-Pieter (2001), Business cycles in the Netherlands, 1815-1913. Working paper, Groningen University.

Johnson, N.J., Backlund, E., Sorlie, P.D. and Loveless C.A. (2000), Marital status and mortality: the national longitudinal mortality study, Annals of Epidemiology, Vol. 10(4), pp. 224-238.

Lillard, Lee A.; and Panis, Constantijn W. A. (1996), Marital Status and Mortality: The Role of Health, Demography, Vol.33, No.3., pp. 313-327.

Lumey, L.H. and Stein, Aryeh D. (1997), In utero exposure to famine and subsequent fertility: the Dutch famine birth cohort study, American Journal of Public Health, Vol. 87, pp. 1962-1966.

Lummaa, Virpi (2003), Early developmental conditions and reproductive success in humans: downstream effects of prenatal famine, birthweight, and timing of birth, American Journal of Human Biology, Vol. 15, pp. 370-379.

Lund, Rikke; Holstein, Bjørn Evald; and Osler, Merete (2004), Marital history from age 15 to 40 years and subsequent 10-years mortality: a longitudinal study of Danish males born in 1953, International Journal of Epidemiology, Vol. 33(2), pp. 389-97.

Maccini, Sharon, and Dean Yang (2009), Under the Weather: Health, Schooling, and Economic Consequences of Early-Life Rainfall, American Economic Review, 99(3), pp. 100626.

Mandemakers, Kees (2000), The Netherlands. Historical Sample of the Netherlands, in P. Kelly Hall, R. McCaa, G. Thorvaldsen (ed.), Handbook of International Historical Microdata for Population Research (Minnesota Population Center Minneapolis), pp. 149177. 
Matthijs, Koen (2003), Demographic and sociological indicators of privatisation of marriage in the 19th century in Flanders, European Journal of Population, Vol. 19, pp. 375-412.

Murray, John E., (2000), Marital Protection and Marital Selection: Evidence from a HistoricalProspective Sample of American Men, Demography, Vol. 37, pp. 511-521.

Petersen, William (1960), The Demographic Transition in the Netherlands, American Sociological Review, Vol. 25(3), pp. 334-347.

Phillips, David I. W.; Handelsman, David J.; Eriksson, Johan G.; Forsen, Tom; Osmond, Clive; and Barker, David J.P. (2001), Prenatal growth and subsequent marital status: Longitudinal study, British Medical Journal, Vol. 322, pp. 771.

Power, Chris; Li, Leah; Manor, Orly; and Davey Smith, G. (2003), Combination of low birth weight and high adult body mass index: at what age is it established and what are its determinants?, Journal of Epidemiology and Community Health, Vol. 57, pp. 969-973

Sloboda, Deborah M., Hickey, Martha; and Hart, Roger (2011), Reproduction in females: the role of the early life environment, Human Reproduction, forthcoming.

Vågerö, Denny; and Modin, Bitte (2002), Prenatal growth, subsequent marital status, and mortality: longitudinal study, British Medical Journal, Vol. 324, pp. 398.

Van den Berg, Gerard J., Doblhammer, Gabriele, and Christensen, Kaare (2011), Being born under adverse economic conditions leads to a higher cardiovascular mortality rate later in life: Evidence based on individuals born at different stages of the business cycle, Demography, forthcoming.

Van den Berg, Gerard J., Lindeboom, Maarten and López, Marta (2009), Inequality in individual mortality and economic conditions earlier in life, Social Science and Medicine, Vol. 69(9), pp. 1360-1367.

Van den Berg, Gerard J., Lindeboom, Maarten and Portrait, France (2006), Economic Conditions Early in Life and Individual Mortality, American Economic Review, Vol. 96(1), pp. 290-302.

Van den Berg, Gerard J., Lundborg, Petter, Nystedt, Paul; and Rooth, Dan-Olof (2010), Critical periods during childhood and adolescence: a study of adult height among immigrant siblings, Working paper, Lund University.

Van Poppel, Frans,(1992), Trouwen in Nederland: Een Historische-Demografische Studie van de 19e en Vroeg-20e Eeuw, Working paper, NIDI, The Hague.

Van Poppel, Frans; and Joung, Inez (2001), Long-Term Trends in Marital Status - Mortality Differences in the Netherlands 1850-1970, Journal of Biosocial Sciences, Vol.33, pp. 279 303. 
Wolleswinkel-Van den Bosch, Judith H.; Van Poppel, Frans; Tabeau, Ewa; and Mackenbach, Johan P. (1998), Mortality decline in the Netherlands in the period 1850-1992: a turning point analysis, Social Science and Medicine, Vol. 47(4), pp. 429-443.

Wong, Linda Y. (2007), Labor market development and marri-age, Working paper, Binghamton University. 
Table 3: Parameter estimates for the full model with interactions between age and conditions at birth in the causal effect of marriage on the mortality rate (first out of three parts of the table)

\begin{tabular}{|c|c|c|c|c|c|c|}
\hline \multirow[t]{2}{*}{ Variable } & \multicolumn{2}{|c|}{ Full Sample } & \multicolumn{2}{|c|}{ Men } & \multicolumn{2}{|c|}{ Women } \\
\hline & Est. & t-stat. & Est. & t-stat. & Est. & t-stat. \\
\hline \multicolumn{7}{|c|}{ Individual background characteristics affecting the marriage rate: } \\
\hline Female & 0.45 & 9.46 & & & & \\
\hline Social class father at birth & -0.08 & -4.35 & -0.11 & -4.00 & -0.04 & -1.55 \\
\hline Father is literate & -0.11 & -1.52 & -0.03 & -0.27 & -0.13 & -1.38 \\
\hline Born in urban area & -0.07 & -1.30 & 0.09 & 1.15 & -0.20 & -2.53 \\
\hline Born in province Utrecht* & 0.04 & 0.75 & 0.12 & 1.42 & 0.02 & 0.27 \\
\hline Born in province Zeeland* & 0.17 & 3.24 & 0.10 & 1.27 & 0.24 & 3.40 \\
\hline \multicolumn{7}{|c|}{ Business cycle conditions early in life affecting the marriage rate: } \\
\hline Boom (instead of recession) at birth & -0.04 & -0.70 & -0.01 & -0.16 & -0.08 & -0.98 \\
\hline cator for age 1 up to 6 & -0.01 & -0.19 & -0.12 & -1.50 & 0.03 & 0.46 \\
\hline Cycle indicator for age $7 \mathrm{u}$ & -0.11 & -1.97 & -0.21 & -2.46 & -0.08 & -0.98 \\
\hline Cycle indicator for age 13 up to 15 & -0.04 & -0.22 & 0.14 & 0.54 & -0.28 & -1.29 \\
\hline \multicolumn{7}{|c|}{ Exposure to epidemics early in life affecting the marriage rate: } \\
\hline 1849 Cholera in Utrecht during age 1-6 & -0.12 & -0.09 & -0.05 & -0.02 & 0.08 & 0.05 \\
\hline 1870 & -0.89 & -1.98 & 0.12 & 0.21 & -1.82 & -2.77 \\
\hline 1849 Cholera in Utrecht & -2.37 & -1.58 & -1.90 & -0.93 & -2.98 & -1.26 \\
\hline pox during & 0.03 & 0.06 & -0.11 & -0.15 & 0.02 & 0.02 \\
\hline 1849 & -3.43 & -2.95 & -3.01 & -1.73 & -3.17 & -1.85 \\
\hline 1870/1 smallpox during age $13-15$ & 1.15 & 2.44 & 0.42 & 0.63 & 1.27 & 2.02 \\
\hline \multicolumn{7}{|c|}{ Contemporaneous macro conditions affecting the marriage rate: } \\
\hline 1849 cholera in Utrecht & -0.42 & -1.01 & -0.28 & -0.48 & -0.56 & -0.95 \\
\hline 1870 & -0.02 & -0.11 & -0.13 & -0.56 & 0.11 & 0.50 \\
\hline 1918 & 0.14 & 0.92 & 0.16 & 0.72 & 0.14 & 0.69 \\
\hline (GNP missi & -3.12 & -4.07 & -2.34 & -2 & -4.45 & -3.84 \\
\hline Current Trend (log annu & -0.23 & -2.71 & -0.17 & -1.44 & -0.33 & -2.94 \\
\hline Current Cycle (log annual real 1 & 0.20 & 0.63 & 0.16 & 0.60 & -0.06 & -0.15 \\
\hline \multicolumn{7}{|l|}{ Age effect on marriage rate: } \\
\hline$\eta_{0}^{m}$ & -9.39 & -7.10 & -9.56 & -5.58 & -15.98 & -5.07 \\
\hline$\eta_{1}^{m}$ & -8.88 & -5.81 & -8.05 & -4.40 & -19.41 & -4.69 \\
\hline$\eta_{2}^{m}$ & -13.39 & -8.59 & -14.27 & -7.17 & -22.95 & -5.81 \\
\hline$\eta_{3}^{m}$ & -3.83 & -4.51 & -3.63 & -3.46 & -9.04 & -4.25 \\
\hline$\eta_{4}^{m}$ & -4.72 & -10.15 & -5.30 & -8.15 & -7.15 & -7.32 \\
\hline \multicolumn{7}{|l|}{ Unobserved heterogeneity terms for marriage: } \\
\hline$v_{m}^{1}$ & -1.73 & -15.78 & -1.81 & -11.99 & -1.40 & -9.56 \\
\hline$v_{m}^{2}$ & 0.60 & 23.73 & 0.67 & 17.41 & 0.77 & 16.53 \\
\hline \multicolumn{7}{|l|}{ Unobserved heterogeneity terms for death: } \\
\hline$v_{d}^{1}$ & 0.16 & 5.68 & 0.14 & 3.511 & 0.17 & 5.618 \\
\hline$v_{d}^{2}$ & -1.24 & -2.66 & -1.25 & -1.65 & -1.41 & -2.36 \\
\hline
\end{tabular}


Table 3: (continued; second out of three parts)

\begin{tabular}{|c|c|c|c|c|c|c|}
\hline \multirow[t]{2}{*}{ Variable } & \multicolumn{2}{|c|}{ Full Sample } & \multicolumn{2}{|c|}{ Men } & \multicolumn{2}{|c|}{ "Women } \\
\hline & Est. & t-stat. & Est. & t-stat. & Est. & t-stat. \\
\hline \multicolumn{7}{|c|}{ Individual background characteristics affecting the mortality rate: } \\
\hline Female & -0.16 & -3.96 & & & & \\
\hline Social class father at birth & 0.00 & 0.17 & 0.02 & 0.68 & -0.02 & -0.86 \\
\hline Father is literate & -0.02 & -0.31 & -0.07 & -0.79 & 0.05 & 0.54 \\
\hline Born in urban area & 0.07 & 1.42 & 0.21 & 2.89 & -0.06 & -0.81 \\
\hline Born in province Utrecht* & 0.25 & 4.74 & 0.23 & 3.12 & 0.28 & 3.67 \\
\hline Born in province Zeeland* & 0.13 & 2.67 & 0.08 & 1.10 & 0.17 & 2.49 \\
\hline \multicolumn{7}{|c|}{ Business cycle conditions early in life affecting the mortality rate: } \\
\hline Boom (instead of recession) at birth & -0.12 & -1.63 & -0.32 & -3.08 & 0.17 & 1.40 \\
\hline Cycle indica & 0.02 & 0.44 & 0.03 & 0.47 & 0.01 & 0.19 \\
\hline Cycle indicator for age 7 up to 12 & -0.14 & -2.74 & -0.17 & -2.36 & -0.09 & -1.24 \\
\hline Cycle indicator for age 13 & 0.18 & 0.93 & 0.14 & 0.54 & 0.28 & 1.14 \\
\hline \multicolumn{7}{|c|}{ Exposure to epidemics early in life affecting the mortality rate: } \\
\hline 1849 Cholera in Utrecht during age 1-6 & 0.57 & 0.55 & -0.38 & -0.27 & 0.98 & 0.68 \\
\hline $1870 / 1 \mathrm{sn}$ & -1.61 & -3.50 & 3.31 & 2.58 & -1.70 & -2.57 \\
\hline 1849 Cholera & 1.80 & 1.84 & -1.38 & -2.14 & 0.14 & 0.09 \\
\hline $1870 / 1$ sma & -1.55 & -3.00 & -1.06 & -1.51 & -2.37 & -3.04 \\
\hline 1849 Chol & -0.88 & -1.30 & -1.20 & -1.03 & -0.96 & -1.12 \\
\hline 1870/1 smallpox during age $13-15$ & 0.44 & 1.02 & 0.63 & 0.99 & 0.08 & 0.15 \\
\hline \multicolumn{7}{|c|}{ Contemporaneous macro conditions affecting the mortality rate: } \\
\hline 1849 cholera in Utrecht & 1.14 & 2.52 & 1.55 & 3.07 & 0.31 & 0.31 \\
\hline $1870 /$ & 0.57 & 2.41 & 0.35 & 0.97 & 0.74 & 2.37 \\
\hline $1918 \mathrm{infl}$ & -0.08 & -0.40 & -0.02 & -0.08 & -0.12 & -0.42 \\
\hline World War II (GNP missing) & -4.86 & -11.38 & -3.55 & -5.57 & -6.62 & -10.66 \\
\hline Current Trend (log annual rea & -0.60 & -11.98 & -0.45 & -6.05 & -0.80 & -10.93 \\
\hline Current Cycle (log annual real p.c. GNP) & -0.28 & -1.13 & 0.00 & 0.00 & -0.31 & -1.03 \\
\hline \multicolumn{7}{|l|}{ Effect of marital status on the mortality rate: } \\
\hline$\eta_{0}^{a p e}$ & 0.16 & 0.84 & -0.18 & -0.50 & 0.33 & 1.38 \\
\hline$\eta_{1}^{a p e}$ & 0.23 & 0.35 & -0.05 & -0.11 & 0.54 & 1.06 \\
\hline$\eta_{2}^{\text {ape }}$ & -0.06 & -1.17 & -0.06 & -0.88 & -0.08 & -1.03 \\
\hline$\eta_{3}^{\text {ape }}$ & 0.68 & 0.34 & 1.04 & 2.03 & 0.43 & 0.91 \\
\hline$\eta_{4}^{\text {ape }}$ & -0.04 & -0.77 & -0.09 & -1.07 & -0.02 & -0.26 \\
\hline Age $\times$ boom at birth $\left(\eta_{0}^{a, i n t}\right)$ & 0.02 & 0.07 & 0.08 & 0.18 & -0.09 & -0.31 \\
\hline Age $\times$ boom at birth $\left(\eta_{1}^{a, i n t}\right)$ & -0.18 & -0.60 & -0.12 & -0.19 & -0.23 & -0.64 \\
\hline Age $\times$ boom at birth $\left(\eta_{2}^{a, i n t}\right)$ & 0.36 & 0.98 & 0.22 & 0.30 & 0.55 & 1.16 \\
\hline Age $\times$ boom at birth $\left(\eta_{3}^{a, \text { int }}\right)$ & -0.38 & -1.60 & -0.29 & 0.64 & -0.46 & -1.54 \\
\hline Age $\times$ boom at birth $\left(\eta_{4}^{a, i n t}\right)$ & 0.23 & 1.43 & 0.18 & 0.68 & 0.30 & 1.33 \\
\hline
\end{tabular}


Table 3: (continued; third out of three parts)

\begin{tabular}{c|c|c|c|c|cc}
\hline \hline Variable & \multicolumn{2}{|c|}{ Full Sample } & \multicolumn{2}{c|}{ Men } & \multicolumn{2}{c}{ Women } \\
\hline & Est. & t-stat. & Est. & t-stat. & Est. & t-stat. \\
\hline Age effect on the mortality rate: & & & & & & \\
$\eta_{0}^{d}$ & 1.29 & 3.17 & 0.24 & 0.39 & 2.62 & 4.41 \\
$\eta_{1}^{d}$ & 1.94 & 24.65 & 1.83 & 14.19 & 2.13 & 19.94 \\
$\eta_{2}^{d}$ & 0.83 & 7.97 & 0.71 & 3.91 & 1.01 & 7.20 \\
$\eta_{3}^{d}$ & -0.05 & -0.73 & -0.12 & -1.09 & 0.03 & 0.31 \\
$\eta_{4}^{d}$ & -0.14 & -1.78 & -0.23 & -1.82 & -0.02 & -0.16 \\
Joint probabilities of unobserved heterogeneities: & & & & \\
$q_{1}$ & 0.39 & 14.38 & 0.42 & 10.24 & 0.48 & 12.12 \\
$q_{2}$ & 0.41 & 15.69 & 0.40 & 11.26 & 0.33 & 9.36 \\
$q_{3}$ & 0.11 & 5.10 & 0.11 & 3.16 & 0.13 & 4.98 \\
$q_{4}$ & 0.09 & 4.28 & 0.07 & 2.53 & 0.07 & 3.38 \\
\hline$-\log$ likelihood & 33374.03 & 16941.33 & 16299.30 \\
Number of individuals & \multicolumn{3}{c}{5593} & \multicolumn{2}{c}{2709} & 2884 \\
\hline
\end{tabular}

